\title{
Dawkins and Incurable Mind Viruses? Memes, Rationality and Evolution
}

\author{
R. S. Percival
}

ABSTRACT

Dawkins tries to establish an analogy between computer vinuses and theistx belief systems, analyzing the latter in terms of his concept of the meme. The underlying thrust of Dawkins argument is to downplay the role o! truth and logic in the survival of theories and to emphasize humankind's helpless liability to incurable infection by doctrines that Dawkins regards as absurd. Dawkins supplies a list of "symptoms" of mind-infection. but on closer investigation these charactenstics are found to be either rather weak protection against criticism or quite virtuous. Dawkins relies on a crude justificationism that could just as well be called a mind-virus. Applying Dawkins own selection of the general characteristics of a good meme protoctor and propagator kads to the conclusion that his particular theistic examples would actually impait copyabithy. Scentific theories are better examples of memes with high longevity, fecundity, and fidelity. A Darwinian analysis of wishful and fearful thinking as useful to hypotheses-testing and goal-seeking organisms undermines Dawkins' attribution of absolute irrational stubbornness to theises. To counterbalance Dawkins' emphass on the propagation of the absurd. I rehabilitate the Socratic emphasis on the imponance of truth and loge in rtetonc, interpreted broedly the theory of the successful propagation of a message. I uxe Popper's notion of situational andysis, and an evolutionary perspecilve to argue that rational standands of a message enhance its copyability. I further apply Popper 5 notions of Worlat 1,2 , and 3 to memes, this helps us see the perpetuation of a doctrine as a logeal task

\section{Introduction}

Can a theoretical system be reproduced through a population of human minds regardless of its correspondence to reality and human reason?

In Daukins' paper "Is God a Computer Vinus?" (1993), be argues that doctrines such as theism, faith. holy mysteries, etc. are like computer viruses in that they are disruptive errors whose ublyuitous presence is due umply to their exceptional capacity to induce their carners to replicate them. Just as a biological virus subverts the machinery of the cell to make copies of itself or a computer vins subvers the machinery of the computer to make copies of itself. so absurd theones about the world can spread remarkably well through humun brains by exploitung two of their outsuanding features. Human brains,

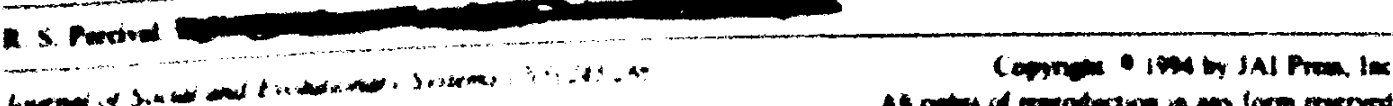

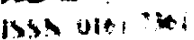

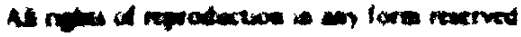


especially young ones, are both ready and able to copy information and also obey instructions embodied in the information. Dawkins' theory can be put briefly this way. Absurd doctrines will survive and spread to the extent that they: (1) instruct, command or otherwise motivate the carrier to copy them, and (2) incorporate or associate with attitudes, lifestyles, or instructions that avoid, repress, or make irrelevant undermining evidence and rival doctrines.

Some theories, Dawkins asserts (1976/1990, p. 198), can exploit blind faith, so that absurdity not only enhances an idea's copyability but makes it secure against counterevidence: "Another member of the religious meme complex is called faith. It means blind trust in the absence of evidence, even in the teeth of evidence." Dawkins is not alone in the attribution of absolute stubbornness to certain types of doctrine. Thus, Kolakowski $(1978$, p. 452) writes, 'Not only in the 'socialist bloc,' where the authorities used every means to prevent information seeping in from the outside world, but also in the democratic countries, the Communist parties had created a mentality that was completely immune to all facts and arguments 'from outside,' i.e., from 'bourgeois' sources."

The supposition that there are "mind-viruses" is part of Dawkins' general theory of memetic evolution. In The Selfish Gene (1976/1990), Dawkins developed the theory that with the emergence of the human brain a new type of replicator came into existence. He called this the meme, a general term which includes ideas, theories, designs, tunes, fashions, etc. Dawkins thinks that trying to explain culture in Darwinian terms is worthwhile, but that not all cultural phenomena can be reduced to genes and their evolution. The Darwinian process of selection is a much more general notion than that, and it can be applied to the evolution of memes. He makes very plain that memetic evolution can be quite independent of our genetic evolution. The meme for celibacy, for instance, Dawkins argues, is clearly independent of genetic evolution; it hardly increases the genetic reproducibility of those humans who replicate the meme. What is important for Dawkins is that once brains developed the capacity and tendency for imitation (perhaps but not necessarily to imitate genetically fit behavior of adults), memes that were neutral or even maladaptive could get spread about. Ruse (1986, p. 178) says that "All beliefs have their roots in adaptive advantage." But even fatal memes can survive if their carriers pass them on before they die; or a meme, such as the Chinese policy of limiting births to one per family, may simply lower the fertility of those who adopt it, giving no individual a genetic advantage. To reinforce Dawkins' point, even if the spontaneously generated new memes where originally conducive to genetic reproducibility, errors in imitation (replication) could produce
variants subject to other non-genetic criteria of selection. be adopted for quite another use. [Editor's Note I: See. Memes adapted to one use may article in this Issue for references on "pre-adapation" See my Note at the end of Verhulst's adaptation in other, quite different ones-notiation, "or the use of traits evolved for one

In any case, the right conditions for aticed by Darwin.-PL]

present. Ideas, fashions, tunes (memes in a Darwinian evolutionary process seem to be variation, differential elimination, and general) are subject to at least a degree of blind position point to the dissimilarities beteproduction. Superficial criticisms of Dawkins' evolution is faster than genetic evolutieen genetic and cultural evolution, that cultural culture, and that the transmission of cun that there is more chance of hybridization in criticisms miss the point: what is being asse is Lamarckian (Hallpike, 1988). But these identical; the general conditions are asserted is that the two processes are similar not 
transmission is Lamarckian, one can cheerfully accept this, pointing out that each stage of a Darwinian process-variation, differential elimination, and reproduction-can contain both planned and blind elements.

This is perhaps an appropriate place to offer a sketchy, bird's-eye view of how memetic evolution fits into an overall scheme of evolution. This will also enable me to indicate the role of purpose within the broad scheme. I think we can usefully distinguish four types of evolution, emerging in the following sequence. (This schema is meant for expository purposes, and not as a complete list of types of evolution. Worlds 1, 2, \& 3 are Popper's terms for the domains of physics, psychology, and abstract entities such as theories and arguments.)

1) evolution of inanimate matter

2) phylogenetic and ontogenic evolution of the brain

3) phylogenetic and ontogenic evolution of the mind

4) memetic evolution, selection occurring over the output of many brains

\}orld 1

World 1

World 2

\} World 3

Characterizing each type is a cluster of mechanisms (operating according to propensities) ${ }^{1}$ of blind variation, differential elimination, and reproduction. As Popper has argued, each type is emergent, in the sense that although the previous type made it possible, it has autonomous properties, laws, and relations unpredictable from the previous type. Although each type cannot be predicted from the older types, it can be understood as a solution to problems presented by the previous type. With the emergence of each type we witness the emergence of new units of selection and new modes and criteria of variation, selection and reproduction. Each type helps to set up the structure of the next type, a structure which then influences and constrains how the older types influence it. In "Of Clouds and Clocks," Popper (1965, in 1972) speaks of each new type as exercising "plastic" control over the older types. Cosmological evolution was completely blind until the emergence of goal directed action in organisms and later conscious purpose in the hominid brain. But the emergence of purpose does not exclude a Darwinian analysis. I must stress that the human brain thinks according to a Darwinian-like process with an admixture of design: (1) partly blind, partly designed variations; (2) partly blind, partly designed selection; (3) partly blind, partly designed reproduction.

For example, a scientist may consciously search in a planned way for the solution to a consciously formulated problem, perhaps using the technique of "brain storming" to enhance variation, but the particular new trial hypotheses the scientist will produce are unforeseeable (blind); the scientist may plan to critically evaluate each trial solution, but the particular resultant criticisms produced or encountered are unforeseeable; the scientist may plan the application of the solution to new problems (reproduction), but exactly which particular problems it will be applied to and how it will fair the scientist cannot tell. (I think this successfully counters with Zahar's assertion (1989, p. 23), that the progress of science is Lamarckian and not Darwinian.) Campbell (1960) points out that systematic methods of discovery or problem solving (e.g., Zahar's heuristics) are the result of earlier processes of blind selection and retention processes. Expanding this, one can say that even Lamarckian-like elements-designs, plans, instructions, and goals-are a result of previous processes of blind variation, selection, and reproduction. (Popper 
mentions this possibility in "Of Clouds and Clocks", p. 253.) (Ramsay Steele's paper "How We Got Here," 1988, is also an excellent corrective to those theorists, such as Hallpike (1986) who assume that for a phenomenon to be given a Darwinian explanation the phenomena have to be completely blind. ${ }^{2}$ )

Interestingly, each stage of the process-variation, selection, reproduction-can itself incorporate all three stages, allowing the possibility of a complex nested hierarchy. Thus the output of one cluster of processes may be the input to another at any of the three stages.

Of supreme importance in this scheme of evolution is the emergence of the autonomous world of theories and arguments, of logical and mathematical properties and relations. This constitutes Popper's World 3. The natural numbers may have been invented, but once invented do not need our constant psychological maintenance; and their properties, e.g., the pattern of the prime number sequence, may be completely astonishing, having a feedback on our thinking and technology unpredictable from our psychology.

I will be arguing that the output of the phylogenetic evolution of the brain is a brain with certain criteria of selection of ideas. (These are similar to, but not the same as, Edelman's [1987] "values" in his theory of neural Darwinism. They can perhaps be viewed as abstract constraints over the selection of ideas related to any particular values such as sex, food, etc.) Human brains prefer to adopt, maintain in memory, and spread networks of ideas that have the following properties:

i) logically consistent and abide by the rules of logic;

ii) more truth-like and of higher logical and information content than their rivals;

iii) systematically organized with few premises;

iv) solve their problems better than their rivals;

v) do not contain unfeasible demands or ineffective means;

vi) do not contain excessive economic demands, an economic demand being an
opportunity cost; and

vii) help render emotions appropriate to the world.

Because of certain new constraints introduced by World 3 objects and the memes satisfying these rationological and logical of transmitting a meme through imitation, etc., brain and also from brain to brain.

I take very seriously Popper's emphasis on the autonomy of World 3 objects, and see them (e.g., the law of contradiction) not only as exerting a selection pressure during
the mental life of any individual, but also in the mental life of any individual, but also in the transmission of memes from brain to
brain and, to some extent, during phylogeny mathematics in the course of our phylogenetic evudimentary anticipations of logic and pressures themselves, reinforcing the trend toward greater may well have acted as selection seen if we accept that World 3 objects have an independentionality. This is more easily our thoughts, hopes and plans. Regrettably, two of the most nature that may clash with theory of memes and Edelman's neural Darwinism, pay most exciting theories, Dawkins' or completely fail to see its autonomous, objective no heed to World 3 (Dawkins) breathtakingly reduces by implication odd and objective nature (Edelman). Edelman theorem and Fermat's last theorem to "stable mental obers, prime numbers, Goldbach's by the fact that this World 3 is our product. 
I will be arguing that all memes are in fact World 3 objects-or, to be more precise, they have a tripartite structure partaking of Worlds 1, 2, and 3. Even fashions and tunes have a World 3 aspect, not only because of their abstract character, but also because all memes are adopted for a use and there is a theory behind any means-end relationship. Memes can thus be thought of as the World 1 and 2 phenotypic embodiment of an associated (conscious or unconscious) theory (World 3) - the theory being analogous to a gene-complex. We need to acknowledge this because it clearly shows the relevance of truth to memes, and therefore the relevance of sound criticism or, in general, counterevidence.

The underlying thrust of Dawkins' target article (1993) is to downplay the role of truth, logic, and rationality in the survival of memes, and to emphasize our helpless vulnerability to incurable infection by doctrines regarded by Dawkins as absurd. He is not unique in this attitude, and I will examine some other points of view in developing my case.

In response to this popular cynical view that truth and rationality are either irrelevant or an impediment to the copyability of memes, I will argue the following: Dawkins supplies a list of "symptoms" of mind-infection, but on closer investigation these characteristics are found to be either rather poor protection against criticism or highly virtuous traits found in business, invention, and science. Dawkins utilizes a crude justificationism that is not only philosophically flawed, but could just as easily be called a mind-virus according to Dawkins' definition. We do well to focus on this because many theorists who attribute irrationality to humans do so because they have been misled by their unexamined adherence to impossible justificationist standards. Dawkins (1976/1990) asserted that the properties that make a gene good at propagating itself are longevity, fecundity, and copying-fidelity. But if, as Dawkins further says (p. 194), the same applies to memes, then one must conclude that Dawkins' particular theistic examples would actually impair their own copvability-i.e., I contend that immunizing stratagems and other evasive moves to "protect" a meme from criticism (common techniques of theistic argument) actually impair rather than enhance its copyability. I will show that scientific theories are in contrast better examples of memes with high longevity, fecundity, and copying-fidelity, and this is because of the rational elements they embody and utilize. These elements have contributed to the successful spread of science, not only because they satisfy general selection criteria (values) of the human cognitive system. but also because they are more copyable within brains (memory) and between brains.

Further, memes such as "heaven" and "hell" arguably are sustained by wishful and fearful thinking. commonly regarded as irrational. But a Darwinian analysis of wishful and fearful thinking as useful to hypotheses-testing and goal-seeking organisms undermines Dawkins' attribution of absolute irrational stubbornness to theists-i.e., I will contend that such apparently irrational thinking has rational components.

To counter Dawkins' emphasis on the propagation of the absurd, I'll call upon the Socratic emphasis of the importance of truth in rhetoric, interpreted broadly as the propagation of a message. Ill employ Popper's concept of situational analysis and an evolutionary perspective to argue that rational aspects of a message facilitate and augment its copyability.

There are lifestyles. organizations and systems of ideas, that inhibit a critical ethos. But none of these provides an absolutely secure niche for erroneous ideas to replicate. 
On the other hand, I want to uphold the supreme importance of promoting a critical ethos--the institutions, attitudes, and methods that make possible both the maximum production of competing ideas and their severe criticism.

\section{Mind-Virus Detection Kit}

Dawkins says that like the computer virus the successful "mind virus" will be difficult to detect. But there may be tell-tale signs. Just as there are computer virus detecting programs that look for symptoms of infection, so one might put together a list of symptoms that an infected mind might have. Dawkins suggests the following.

- a compelling belief that "owes nothing to evidence or reason";

- the person makes a "positive virtue" out of "strong and unshakeable" belief in the absence of evidence; because this belief refers to itself;otherwise awkward requests for the evidence for this virtue are undermined-at least in the eyes of the believer;

- mystery per se is regarded as a good thing, something to be savored, not solved; again, this belief refers not only to particular "mysteries" (such as Transubstantiation and the Trinity) but also to itself, and thus forms a psychological barrier not only to the criticism of a "mystery" but also itself; an extreme version of this is Tertullian's "certum est quia impossibile" (it is certain because it is impossible).

Let's look at this last symptom in more detail. Dawkins is particularly concerned in his article (1993) with those memes, like Tertullian's creed, that are self referential, that enjoin or otherwise induce their carriers to protect them from criticism. Dawkins fails to mention that some of these characteristics are equivalent to Popper's "immunizing stratagems" and "ad hoc hypotheses"(Popper, 1934) and "reinforced dogmatisms" (1963). refutation. An example is the reinterpretation of a theory or evidence in order to avoid the world would end in 1914 to mean thation of the Jehovah's Witnesses' prediction that in heaven (see Wells, 1988). An ad hoc hat this was the year Jesus Christ was crowned anomaly, the result not adding to the theorsesis is introduced to cater to a particular it. An example is provided by Velikovsky's information content, and possibly reducing originally a comet which, after a catastrophic acording to whom the planet Venus was the gravity of the solar system. Velikovsky predicteds of the Earth, became trapped by record of this event. However, when no records of that all civilizations should have a the literature of many communities of the time Veliktraordinary events were found in supposing that everyone at this time had suffelikovsky swept this difficulty aside by Tertullian's creed is an example of what Popper calls shock-induced amnesia. Lastly, dialectic, which even more explicitly repudiates a "reinforced dogmatism." Hegel's example. These ideas are reinforced dogmatisms becaus of contradiction, is another criticism, since any straightforward criticism of ause they seem to disarm all possible contradiction between the theory and a description a theory consists of pointing to a the theory itself. 


\section{Continuing with Dawkins' list of mind-infection symptoms, we find the following:}

- the believer behaves intolerantly toward believers of other faiths, repressing their publications or speech, even killing them; the Catholic church's extermination of the Albigensian sect is perhaps a good example;

- the epidemiology of the belief is more important than evidence in accounting for its adoption; hence, so Dawkins maintains, most children adopt and spread the religion of their parents; children do not rationally choose between the religions of the world, but more or less invariably copy the religion of their parents simply because it happens to be the one around;

- the person's experience of the doctrine is like that of sexual love.

\section{Dawkins' Viral Detector Program Itself Has a Virus}

Let me begin my in-depth response to Dawkins by quarreling with the blatant justificationist prejudices in his characterization of the "infected" mind. Dawkins assumes that there is some virtue in beliefs which "owe something" to evidence, presumably either logically derived from or engendered by evidence or reason. But this wide-spread assumption is itself in Dawkins' own terms a viral infection of Dawkins' viral detector program. The first tell-tale symptom is the very vagueness with which the principle is stated. We may reformulate it thus: Accept all and only those positions that can be justified (by reason or evidence); reject all others. This is the principle of justificationism. The problem with this is that this itself is not based on evidence or reason. But if Dawkins' follows the principle then he must justify the principle itself. As Fries (1828-31) argued, justificationism issues in the following trilemma. To avoid dogmatism one must be able to justify the statements of science. But statements can, logically, only be justified by other statements. This leads to an infinite regress. The only alternative left, Fries argued, is that statements be justified somehow by immediate experience, a methodologically unsound solution called psychologism by Popper (1934/1959).

One has to bear in mind that Fries took justificationism for granted. Bartley (1984) argued that if one drops justificationism then Fries' trilemma can actually be interpreted as a dilemma engendering dilemma. According to Bartley's non-justificationist interpretation of Fries, Dawkins has three options:

1. Simply accept justificationism dogmatically. In which case it is not based on evidence, and is thus a mind-virus on Dawkins' terms.

2. Some evidence or reason is adduced for it. In carrying this out, one will have to introduce some new premise(s) from which the principle of justificationism will be inferred. But then one must, in accord with the principle, ask how these premises are themselves justified. Either one stops at this point, in which case one has to accept something not based on evidence, or one is committed to an infinite series of justifications, a commitment that cannot be fulfilled. Thus in either case one cannot successfully base the principle on evidence. Hence one has a mind-virus. 
3. Justify the principle by immediate experience. But as Popper has argued, to derive universal statements of science from statements describing immediate experiences is logically impossible, since the former go far beyond anything contained in the experience. Nor can one derive even singular statements from immediate experience, such as "here is a glass of water," because of the universals embedded in it. (Popper, 1934, p. 94.) And statements of what one might take to be of more immediate experience, such as "I am having the experience of a patch of red" or "I am experiencing a red sense datum," are of little value to science, except in certain psychological experiments on visual perception. So how the more abstract principle of justificationism itself can be logically derived from experience is even more unclear. If Dawkins falls back on the assumption that experience simply induces acceptance of the principle, then on his own terms justificationism is just as much a mind-virus as any religion. One will be a justificationist simply because of where and when one was born and the experiences one has largely as a function of this. Had Dawkins been born in China or India of Hindu, Buddhist, or Yogic parents he might well have not adopted the largely Western principle of justificationism, since these traditions reject the justificationist attempt to defend or preserve ideas, theories, or beliefs.

Epistemologically, the origin of a belief is irrelevant as to whether it is rationally held, or indeed as to whether it is true. A belief may be prompted by consulting tea leaves at the bottom of a cup, by intuition, or by an hallucination or a rampaging rally. It may yet be true. And as long as it is held open to criticism, it is rationally held. [Editor's Note 2: See, however, my argument in Mind at Large: Knowing in the Technological Age, Greenwich, CT: JAI Press, 1988, Ch. 2 that criticism is itself not free of the justificationist/ foundationalist problem, since mounting an effective criticism assumes the efficacy of the critical process itself-i.e., places the critical process at the time of its use beyond criticism.$P L$.] Hence, the fact that most children adopt the religion of their parents simply because it happens to be the one around does not exclude rational selection. Moreover, to generate positions for which there is no evidence is arguably a virtue. As long as the ancient Greeks were content to merely "save the appearances"-i.e., not go beyond the evidence at hand-they could not develop their science. All the great scientific theories owe very little or nothing to the evidence-they transcended and sometimes contradicted the prima face evidence, as with Aristarchus' theory that the Earth orbited the sun and not vice versa, or the more recent theory of dark matter.

Nor is strong belief per se clearly a vice. All successful action requiring great persistence, in scientific and economic pursuits, requires strong belief; not only strong belief, but deliberately strengthened and sustained belief. Edison failed 11,000 times before he invented the electric light bulb. After 5,000 failures he told a scornful journalist: "I have simply found 5,000 ways not to do it; I must be getting nearer the right one." However, if the methods of strengthening belief involve the exclusion of counter-evidence, then we may speak of an intellectual vice; but the exclusionary method is what is vicious, not the strength of the belief.

What is significant about Dawkins' position is that certain beliefs are alleged to be "unshakeable" and that this must enhance the copyability of the belief. However, immunizing stratagems and ad hoc defenses are not as powerful as one might think in perpetuating a meme. The Jehovah Witness Watch Tower Society lost many members because of repeated 
disconfirmations, despite its use of prophecy-reinterpretations, especially after its failed prediction of the end of the millennium in 1975 (Penton, 1985) ${ }^{4}$ Velikovsky's hypothesis of collective amnesia is amenable to criticism, depending on the implicit theory of amnesia, and the original theory about Venus having been a comet is presumably testable on its implications about the current structure of the Solar System. One can also explain the methodological weakness of Velikovsky's ad hoc defense. Even philosophically unsophisticated people are sensitive to such tactics, as witness the common phrase "changing the goal posts." Tertullian's creed is a challenging example, but even this is susceptible to sound and persuasive criticism. If we are to accept that something is certain because it is impossible, then we have no excuse for rejecting anything else, such as my claim to be Jesus Christ. If this is so, then any doctrine whatever can claim to be the one and only true original doctrine. Each "copy" of the doctrine may be unshakeable, but at the price of massive mutations as it is spread from brain to brain. If this criticism is rejected, I think this means either that the advocate is disingenuous, in which case the belief is not a mind-virus, or that some other assumptions are at work in the advocate's mind. One then needs to tease these assumptions out into the open. Dawkins supplies no case against the feasibility of doing this.

Religion is not the exclusive preserve of mystery. Anyone really craving mystery ought to turn to science. Paradoxically, science thrives on mystery, and indeed, produces more mystery than it starts with. As our knowledge grows, so does our conscious ignorance: we have more answers, but we also have more questions. The Aristotelian doctrine that one explains the unfamiliar in terms of the familiar is defunct and actually the exact opposite of the truth on the frontiers of science. The assumption that the speed of light represents the maximum possible speed was used, along with other assumptions, by Einstein to explain the mystery of Mercury's perihelion. But this assumption itself is a mystery, a deeper and stranger one at that, requiring a deeper answer.

Finally, Dawkins says that one's attachment to a mind-virus is like that of sexual love. But we have all heard stories of outstanding scientists and their great lust for their work, working through the night or illness to develop their theory.

\section{Truth, Validity, and other Rational Standards Enhance Copyability}

To indicate my general position and stimulate critical debate, I issue the following summary thesis as a challenge. (The thesis is argued at some length in my doctoral thesis "Openness to Argument," 1992.)

Consider what, on the common view, are the most favorable circumstances for the propagation of a meme: a propagandistic organization whose only interest is the maximum replication of its doctrine, an organization willing to use deception and evasion to achieve its objective. My conjecture is that no propagandistic erroneous network of ideas can guarantee the satisfaction of these two demands: (1) propagate the network without revision and (2) completely insulate itself against losses in credibility and adherents through sound criticism. If a network of ideas is false or inconsistent or fails to solve its intended problem, or is unfeasible, or is too costly in terms of necessarily forsaken goals, its acceptability may be undermined given only true assumptions and valid arguments. Just as every computer virus, given enough ingenuity, can be combated and eliminated, so every "mind virus" can be soundly and persuasively criticized. Even if propagandists were not 
interested in these rational criteria, arguably their audience is. Therefore propagandists sometimes have to make a marginal modification to their doctrine in order to perpetuate any of it. But then we see that the logic of the propagandists' situation forces them and their successors to make a series of incremental repudiations, each partly blind and partly designed, of the original doctrine until the original doctrine is, as an unintended consequence, effectively abandoned. Selection may also take place over the intellectual leaders of the movement, sometimes catapulting into the limelight those whose interpretation of the doctrine fits or matches best the values of their followers. Since these two processes may take decades or even generations, the analogy with biological evolution by numerous successive slight modifications is rather clear.

But why should we expect people to be rational? There are I think two main ways of answering this question. One way is to analyze our mental functions in terms of our evolutionary origin. Lorenz (1973), Popper (1972), Campbell (1974), and Wächtershäuser (1984), and many others advocate the analysis of our cognitive functions in terms of biological evolution. Much of what Popper and Campbell have said on the biological function of our mind and on methodology is essential in solving this problem. Of particular importance for my purposes is Popper's emphasis on life itself as an active problem solving quest, and Campbell's excellent portrayal of organisms as continually creating and testing possible solutions to their problems. But strangely, both Popper and Bartley have made assertions that imply that humanity's evolutionary origins do not bias him toward the rational selection of memes. Thus, Popper writes that "no rational argument will have a rational effect on a man who does not want to adopt a rational attitude" (1945, p. 231). Bartley's general position on psychological/sociological openness to criticism is that "ideologies are retained regardless of the facts; they are not abandoned when they clash with the facts; rather they die out or are eliminated, if at all, together with their carriers" (1984, p. xvii). Popper and especially Bartley seem to view rationality as a rather fragile tradition traceable to ancient Greece, quite a common view. Thus Bartley says (p. xxi):

I do not for a moment believe that man is a rational animal, let alone that men are born with a 'faculty' of reason. Rather, rationality, like consciousness itself, is a comparatively late, and still rather rare, and, where it exists, fragile development. Most individuals exist in a troubled, slumbering fantasy world, and, when most awake, are bound by rigid habits and unconscious patterns of behavior. Comparatively few persons enjoy the give and take of criticism or think to any purpose other than to dominate.

On the contrary, I view the, undoubtedly important, traditional element as reinforcing our biological propensity for rationality. [Editor's Note 3: See also my Mind at Large, ch. 3, "The Biological Basis of Reason," for a similar view.-PL] Of course, our critical World 3 methods and World 2 attitudes can be improved, but these are phylogenetically evolved mechanisms that, fallibly, register error, enable us to recognize improvements,
and can therein wake us rudely Bartley's view of humanity is a puzzle. Blumbering fantasies. The rise of science on influence of competition and imitation Bartley recognizes this and attributes it to the benefited by copying the exploration through the rise of open markets. Individuals competitors in the provision of com, entrepreneurial behavior of their more successful to eliminate unsuccessful trials almmodities. Reflecting critically on one's own behavior 
meet consumer demand. These attitudes of exploration and self criticism became generalized, making science possible. This is what Popper and Bartley would call a situational analysis of the market and the rise of science.

But Bartley does not consider the possibility that the situational logic of the market may have been part of the genetic selection pressure acting on our ancestors; the market seems to be old enough for it to have had some role in fine tuning human rationality. As Samuel Noah Kramer argues, Ancient Sumer had not only a developed market with money, but also groups explicitly promoting free-trade against those who wanted more restriction of trade. ${ }^{5}$ There were trading routes extending over hundreds of miles even during the Stone Age. The basic principle of trade--that the buyer values money less than the goods bought and the seller values the goods less than the money--seems simple enough to have been discovered at least half a million years ago. ${ }^{6}$ If Bartley had focused on this, he may not have dismissed so quickly the existence of a rational faculty. In any case, the same sort of analysis that Bartley applies to the emergence of rationality can be applied to memes to show that they are more open to criticism than Bartley or Popper suppose.

Furthermore, recent work on ancient Chinese texts by A. C. Graham (1989) shows that the emergence of an explicit tradition of critical argument was not an isolated phenomenon. There was active philosophical debate in ancient China, especially by the Mohists and Sophists. Graham shows that the competition of alternative world-views lead to more and more explicit argument and the analysis of argument itself. But 1 do not want to assess Popper's and Bartley's positions here in great depth, for this would take us too far from assessment of Dawkins' position.

The other main way of answering the question of human rationality concerns what Popper would call the situational logic facing the propagandist, some of which I have just outlined above. (For the notion of situational logic or analysis, see Popper, 1972, p. 178.) Popper actually thinks that an evolutionary analysis is a special case of situational logic or analysis. In a situational analysis we attempt to construct a conjectural explanation of an agent's action in terms of our analysis of the problems the situation presents to the agent-the agent's goals, (limited) information, physical and chemical constraints etc. We then analyze how different possible solutions would lead to different sets of new problems and so on in an evolutionary sequence.

\subsection{Phylogenetic Constraints}

As indicated earlier, people because of their evolutionary origin prefer to adopt and spread networks of ideas that have the following properties:

i) abide by the rules of logic;

ii) more truth-like and of higher logical and information content than their rivals;

iii) systematically organized with few premises (Occam's razor);

iv) solve problems better than their rivals;

v) do not contain unfeasible demands or ineffective means;

vi) do not make excessive economic demands;

vii) contribute to making emotions appropriate to the world.

I conjecture that those pre-Homo sapien hominids whose genetic variation in general values most closely approximated these rational characteristics were more likely to survive. 
I must stress that people do not instantly and directly recognize memes with these characteristics, but discern them by a fallible trial and error process, which itself is a product of biological evolution. These genetic propensities are reinforced by objective techniques (such as truth tables) selected for their efficiency in discerning memes that approximate these characteristics. For convenience of exposition, I have labelled each of the above seven aspects of rationality as follows: logical, exploratory, explanatory, problem, instrumental, economic, emotional. As a network of constraints, they characterize any cognitive performance, from walking to the shop for the morning paper to designing an instrument for capturing neutrinos. I argue first, that since logic and truth are always relevant, therefore counter-argument and counter-evidence are always relevant, and, second, that our evolutionary history makes counter-evidence effective.

We consider how each of the seven components figure in this schema.

(i) Logical Rationality: People prefer to adopt means that are logically consistent and abide by the rules of logic. To sustain this, I need not be committed to the thesis that the rules of logic are descriptive laws of thought, as Kant and later Boole (1854) thought. All one needs to suppose is that the human mind strives, fallibly, for consistency as a result of our evolutionary history. We cannot easily suppose that our ancestors had a habit of regarding a lunging sabre-tooth tiger as at the same time dangerous and not dangerous. Those pre-Homo sapiens that had a propensity to neglect the law of contradiction became extinct. Similarly, to ignore the law of the excluded middle - that the tiger must be either dangerous or not dangerous is not true-would have produced fatal outcomes. I might add that an inability to reject the contradiction of a given belief would have produced fatal degrees of hesitation in general. An evolutionary explanation of a function or organ allows that it could have evolved from something quite different by numerous successive the laws of logic would be that even an incipient propensity to think in accord with consideration for any Darwinian-likeductive advantage. I think this is a very serious the hypothesis that somehow logical rules as thought tends to occur in accord with or simulates are present in the brain, but only that $(1984$, p . 51) points out in his criticism of Noamulates the following of these rules. As Searle the fact-if it be a fact--that all human languages seem theory of generative grammar, set of grammatical rules ("deep structures") does seem to conform to essentially the same these rules, just as the fact that falling stones obey not mean that human brains contain that stones contain instructions or rules in order the laws of gravitation does not mean of the sudden phylogenetic emergence of logical obey these laws. Indeed, the admission mode of numerous small steps. [Editor's Note 4: Bules would work against the Darwinian theory of punctuated equilibria-or evolution 4 : But note that S.J. Gould and N. Eldridge's steps is not the only Darwinian mode.-PL] A sudden spurts-argues that numerous small perhaps the ability to act as a single individual, where a toward logical thinking was coordinated and incompatible actions decided. The where a number of actions can be obviously enhanced this ability. The fact that human emence of a central nervous system in a way that simulated following rules of logic first brains evolved a tendency to think a descriptive language (homo habilis) ${ }^{7}$ and later first made possible the development of incipient appearance ${ }^{8}$ This formal understanding formal understanding of logic, an incipient appearance as simple rules of thumb of onding logic may well have made its 
such as "you can't have your cake and eat it." These early developments may have had a feedback effect on brain structures responsible for thinking in accord with logical rules. Those pre-homo sapiens who were more logical in their thinking would presumably remember these maxims with greater efficiency and thus gain more from them, perhaps setting up a positive evolutionary feedback loop. Once the appreciation of elementary rules of logic (e.g., law of contradiction) had emerged, coded in the nervous system and/or language, these propensities would have themselves acted as evolutionary pressures in the evolution of our appreciation of other rules of logic (e.g., Modus Ponens).

Ruse (1986) has made an excellent case for the evolutionary origin of our appreciation of logic, though I think Ruse confuses the question of the origin of our appreciation of logic with the origin of its nature. However, once evolved, logic, like mathematics, has its own autonomous properties that cannot be explained as conducive to reproductive advantage. These properties may take deep insight to discover and can astonish us. An example is Gödel's theorems. But perhaps this should not surprise us too much. That a tool developed for one use has properties (even useful ones) that are irrelevant to this use is hardly surprising, as mentioned earlier. Our opposable thumb evolved perhaps because of its usefulness in grasping tree branches, but this humble origin does not prevent a pilot using it to turn dials flying the Concorde. This is important, for one might well say that our traditional conception of, say, the excluded middle $(P$ vs. $-P$ ) covers undecidable $P$ s, but that such knowledge did not make a difference to behavior, and so its origin could not have resulted from differential selection over behavioral variants. One could then say that we originally developed an intuitionistic appreciation of $P$ vs. $-P$ for reasons not connected with its now classic contribution to knowledge, and then built the classic $P$ vs. $-P$ on this original with the aid of language, at least partly independent of genetics.

In any case, in this article $I$ am arguing that humans are open to argument and counterevidence. Now one might say, on the one hand, that to reject what we encounter in our immediate sensible environment is very difficult and sometimes impossible. However, on the other hand, one might object that this applies only to beliefs and memes concerning our immediate sensible environment (and therefore not to the abstracts of religion and science). The strongest version of this line of argument is propounded by Wells (1988, p. 219) in his attempt to explain why religious ideas survive criticism:

Let me press this point concerning the correction of our ideas by experience. When our ideas about our immediate environment are very incomplete or erroneous, our behaviour is likely to be ill-adapted to our needs, so that we expose ourselves to some immediate unpleasantness. But in this way attention is called to our mistake, and we may be led to rectify it. If, for instance, we act on the belief that ether is a good fire extinguisher, we shall be in for a rude shock, and if we survive the experience, the belief will not survive with us. On the other hand, any ideas we may have formed about the nature of the universe, or about the distant future or past, are unlikely to lead to any noticeably inappropriate reactions on our part. Thus we may well persist in erroneous beliefs of these kinds all our lives without experiencing the smallest surprise or disappointment.

I conjecture that an adequate defense against this argument lies in the evolution of our appreciation of logical rules. My idea is that an appreciation of logic evolved because 
of its utility in handling problems presented by our ancestors' immediate envitonmentfirst perhaps in the avoidance of predators and then in the construction of tools. and later in organized hunting and still later in the capacity to learn and transmit a language. This grants the element of strength in Wells argument: deficiencies in coping with immediate practical problems is a great selection pressure. However. the appreciation of logic was not tied exclusively to thought about the immediate environment. There was no evolutionary reason for this new general ability to be tied to immediate problems, so genera logical reasoning was not eliminated. Analogously, one may learn to count colored beads, but then automatically also be able to count, as an incidental by-product, apples, oranges, cars, and stars. General reasoning ability may have been a lucky advantageous by-product of the selection pressure on our ancestors to deal efficiently with their immediate environment.

Our ancestors were then able to compare alternative plans of action. whether shon or long term. Their decisiveness would be enhanced by the very fact that they could set more readily which plans really were alternatives. And the more abstract their grasp of logic, the longer the time span over which they could plan. More productive processes often require more time to put into effect: for example sacrificing today's fish caught by hand to make a net that will bring in more fish tomorrow.

In addition, they were able to discard those plans. or parts of plans, which were internally inconsistent or conflicted with a general theory about. say. the whereabouts of game. They were able to do this before they committed themselves to a hunt, for instance. instead of having to test directly every promising plan. Borrowing a phrase from Popper. we can say that our pre-homo sapiens could begin to let their ideas die in their stead. They would also be better at fashioning a tool whose manufacture required a sequence of actions of limited permutability (cf. Holloway, 1983). "They could make better use of general theories by inferring their consequences for many particular circumstances. and finally, they could override the sometimes over-generalized effect of Pavlovian conditioning.

This evolutionary analysis of the origin of our appreciation of logic explains the fact noted by "cognitive dissonance theory" (Festinger, Rieken, \& Schachter, 1956) that people prefer to adopt consonant beliefs, attitudes, and behavior. (Although one could argue that the notion of dissonance in this theory covers not only logical inconsistency. but also what might be more aptly described as infelicity, as per Austin, 1962. However. even felicity. as Austin later argued after dropping his earlier exclusive categories of performative and constative utterances, is dependent on truth.) The evolutionary pressures also explain why all the world's logics are extremely similar. As Staal (1967, p. 520) says, "Although it remains uninfluenced by Western logic and stems from an entirely different tradition. Indian logic offers striking parallels to Western logic." The same is true of Chinese logics.

In light of the above defense. we can seen that Wells is misleading when he says in conclusion (p. 219) that "beliefs which admitted of no practical demonstration and could be checked by no intelligible test could be entrusted only to words or to other cquivesal ciphers and symbols which each generation had to interpret afresh according to its lights." This is not the entire picture, because it suggests that all intelligible tests depend on the immediate environment and neglects the check of consistency and more remote and roundabout checks of logical reasoning generally. Moreover, it overlooks the possibility that an appreciation of logic evolved in connection with immediate problems of the environment but whose scope transcended this parochial domain. 
(ii) Exploratory Rationality or Curiosity: People prefer to adopt memes that are more truth-like ${ }^{10}$ and of higher logical and information content than their rivals. The logical content of a theory consists of the class of non-tautologous implications of the theory. The information content of a theory consists of all the theories which are logically incompatible with the given theory. This follows from the technical (as opposed to commonsense) measure of information as that which we do not already know. (If someone tells us something we already know, we receive no information in that communication.) On this definition, Einstein's theory thus is a part of the information content of Newton's theory. The more a theory tells us, the more it forbids.

Theorists often stress how every organ of every organism can be interpreted as embodying fairly precise (though not perfect) knowledge about the part of the world to which it is adapted (e.g., Lorenz, 1973, pp. 22-23). One might well conclude that a preference for a more accurate representation of the world has been an evolutionary advantage since life began, but Wächtershäuser (1984) has argued that the exploration of the world for knowledge as such came after, and was an unintended consequence of, the search by photosynthesizing micro-organisms for food in the form of light. However, we would certainly be surprised if the preference for more information did not pervade the whole structure and function of the human brain. Psychological experiments have found that apes will learn to perform all sorts of actions just so that they can look into another room. I would guess that this is true for all the higher mammals, for all the senses, and that it can be interpreted as a general quest for information. Curiosity and exploration-or the search for information as such, independent of immediate needbecome increasingly apparent as one looks along the phylogenetic series leading to Homo sapiens sapiens. I think that this general quest for information partly explains the successful spread of scientific theories and science itself, because they embody these values.

Making an early contribution to the theory of memetic evolution, Monod (1970, p. 155) attributes the spreading power of an idea to its "performance" and certain innate structures in the mind. The sort of performance Monod has in mind is the power of an idea to give greater coherence and confidence to a society. He seems to conclude from this that the "promotion value (of an idea) bears no relation to the amount of objective truth the idea may contain. The might of the powerful armament provided by a religious ideology for a society does not lie in its structure, but in the fact that this structure is accepted." Douglas R. Hofstadter (1983) quotes Monod approvingly. Munz (1985) has expressed a similar but more extravagant view: the more absurd an idea is the more likely it is to be selected. " But Monod's conclusion does not follow. An idea giving coherence and confidence to a society indeed may be spread by its beneficiaries, but Monod rejects without examination the possibility that the idea's performance may be facilitated by truth.

To put my point in general terms, a false theory may be useful, and spread because of its usefulness. However, the theory may be useful precisely because of the little truth that it does contain. Therefore, although we might be able to imagine cases in which the usefulness (or "performance") of an idea may be independent of its truth content, we ought not accept the validity of Monod's argument, or its conclusion. Many scientific theories have contributed, in unintentional and unforeseeable ways, to a more confident and coherent society, principally through useful technology. And this has contributed to their "spreadability." If we attribute this usefulness in turn to the truthlikeness of the theories, 
then we must conclude, contrary to Monod, that the truthlikeness of our ideas can promote the copyability of memes.

Dawkins espouses a view similar to Monod's, that there are memes whose spread depends only on the fact that they have already spread to a large extent. There seem to be an avalanche effect when a meme, say a pop tune, has spread to a certain extem, and hence the concern with "top $10 \mathrm{~s}$ " and "top $40 \mathrm{~s}$. "But this could be due to two eminently rational factors: the power of the geometric spread of personal recommendation (5 people each tell 5, who each tell 5 etc., giving 78,125 at stage 7$) ;{ }^{12}$ and the fact that most people like most of what most people like (which is not the same as most people like the same

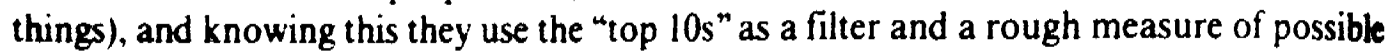
interest. Nor can we overlook the fact that the meme has first to reach the critical avalanche point. [Editor's Note 5: Murray the "K," an eminent disk jockey in New York City in the 1960s, once aptly put the above to me as follow's: If it ain't in the grooves, it wont be a hil. By' which he meant: no amount of record promotion can make a record popular if it doesn't have something in it that is highly appealing. $-P L$.]

I must point out that the objective information content of a theory (on the definition indicated several paragraphs above) is not available for inspection in its entirety because it is in fact infinite. All that is available is what Bartley (1990, p. 39) calls an accessed slice of the theory. So what counts toward the "promotion value" of a theory then must be the current accessed slice of objective information and logical content, or its conjectured content size relative to its rivals. The logical content of theories is more easily compared, though even this is a conjectural process. As Bartley points out, as the accessed slice of a theory changes so also will its economic value. If there is an increase in value, then the theory's copyability is increased; but here then we have another counter-example to Monod's assertion that the promotion value of an idea bears no relation to its objective truth content.

Even non-sophisticated verbal memes such as jokes and urban legends tend to pay some respect to truth. The best jokes do contain a crucial minimum of truth, and when they twist logic for a humorous effect this only works if the distortion is revealed. Urban legends, though often untrue, do describe possible events. Perhaps the old lady, after washing her poodle, did not in fact put it into the microwave to dry it only to find she had cooked it. but one can imagine, at the time this legend came into being, someone doing this without violating one's common sense. (For more on urban legends, see Brunvand. 1989.) Brunvand stresses that most urban legends are mythical, but one cannot easily argue that they would be less memorable or remarkable if they happened to be true. Furthermore. even though jokes and urban legends spread quickly, they have a shorter life than scientific theories. This is because scientific theories have a higher information content and can therefore be usefully applied in a literally infinite number of ways, giving them high fecundity.

(ii) Explanaiory Rasionality: People prefer to adopt memes that are systematically organued, with few premises, and that provide a relatively deeper explanation of a given domain. A religious conversion may resemble the experience of seeing a good explanation in scrence, a good explanation being one that seeks unity in diversity. Émile Meyerson (1908) propused that the human mind instinctively seeks unity in diversity. expressed in science by the xearch for conservation laws and universal theories with few premises. He argued tha the identity principle applies at two levels at the level of laws and at the level 
of things. Laws that are universal, that apply irrespective of time and place, are preferred to local generalizations. With regard to things and processes in the world, the mind prefers to see constant substances behind the transformations. This is how the mind develops conservation laws, such as the conservation of mass and inertia. Meyerson argued that the appreciation of universal laws enables all animals to make predictions useful in the struggle for existence. He doubted whether our appreciation of conservation laws could be given a biological explanation, but as Zahar (1989) points out, the innate postulation of substances that persist in time enables us to keep track of things. Monotheistic religions, reducing the world's diversity to one comprehensive cause, God, which is itself immutable, can be seen as Meyerson's principle of identity in action. Such religions have thus enjoyed a competitive edge because of this. Even polytheistic religions often have a hierarchy of gods, the lesser gods being derived from or at least under the control of those higher up the hierarchy. And animism, arguably the first non-scientific explanation of the world, "allows us to grasp the whole universe as a single entity from a single point of view" (Freud, 19131991 , p. 77). Watkins (1984) has also fruitfully explored what makes a conjunction of statements a unified empirical theory rather than a rag bag collection. ${ }^{13}$

I do have some reservations about Meyerson's theory. The innate ability to distinguish between cases in which the quantity of a substance changes and cases in which it is kept constant despite misleading changes in shape may help us to discover conservation laws, but this is far from an understanding of them. Sometimes the desire for more information (as in $i i$ above) may come into conflict with the identity principle, such as with the law of entropy, which though true throughout the whole of space and time, makes the past and future asymmetrical since an increase in entropy is (presumably) irreversible. In situations like that, the desire for greater truth takes priority. Nonetheless, Meyerson's principle does help us see the similarities of religious and scientific appeals, as indicated above.

Religions of course may serve purposes other than of explanation, as Wittgenstein suggests. Wittgenstein maintained that religion is a form of life, not a belief or opinion. Although I disagree with Wittgenstein, I do not have to be committed to the view that religion is nothing but opinion and belief. As long as there is an element of a desire for explanation in religion, then a principle similar to Meyerson's can play a role in the differential survival of religions. Frazer's account of religions (Golden Bough, 1922), which uses a mine of facts to link ritual with erroneous beliefs and interpretations, was not refuted by Wittgenstein, who simply imposed his alternative theory. The symbolist and fideist views of religion have, in any case, been refuted by such theorists as Jarvie and Agassi (1967) and Jarvie (1972).

(iv) Problem Rationality: People prefer to adopt memes that they interpret as solving some problem. Moreover, they prefer memes that solve problems better than their rivals. This standard can be applied to metaphysical theories that are not amenable to empirical test (Popper, 1934). One may discover that an idea that had seemed such a promising answer to a problem does not in fact have any bearing on it at all. Or one may find that the proposed solution merely shifts the problem. Many possible believers in the existence of a Christian god as an explanation of the existence and ordered complexity of the world dismiss the theistic explanation when they see that the original question can be applied to God itself to generate an infinite regress. Galileo was adept at using this in his arguments for the imperfection of the moon's surface. When believers in the perfection of the moon's 
surface where shown via the telescope the mountains on the moon, they retorted that the moon is after all perfectly spherical anyway, moon's perfect shape. Refusing to offer that fills up the valleys and plains and distribution of the substance, Galileo responded way to check the presence and that the substance was in fact piled up on the mountains,
admitting its existence, but insisted than
making the moon even more imperfect than it seems.

(v) Instrumental Rationality: People prefer to adopt memes that do not contain unfeasible demands or ineffective means. Humans pursue goals that they regard as feasible, and use those means they regard as effective according to their theory of the world and their capacities. Within the scope of their limited and fallible abilities, humans are constantly adapting their means and goals to new evidence insofar as new evidence allows them to reject the unattainable or the ineffective. Psychological experiment has demonstrated that the opportunity for an animal to extend the scope of its control is an effective reinforcer of other behavior, for humans and the higher primates at least.

One of the evolutionary advantages of independent goals, as contrasted with Lorenz's innate releasing mechanisms, is that the organism can change its approach to what it wants depending on the circumstances. If our ancestors had behaved as a fly does when confronted with a pane of glass whenever they could not achieve their objective, they would not have been our ancestors. As a corollary, given that the human brain has limited processing capacity, we would have gained an evolutionary advantage in abandoning the serious pursuit of wishes or goals that had been shown to be utterly unattainable, thus freeing the brain to focus on achievable goals.

The first two criteria (in [i] above), truth and logic, are more easily seen as relevant to factual statements and assumptions and not to all memes. But in so far as other memes, such as tunes or fashionable behavior, are also instruments serving certain ends by certain means, there is a theoretical understanding behind their use which may contain falsity or inconsistency. These background assumptions, then, can in principle be soundly
criticized.

Thus memes whose adoption requires unfeasible acts can be psychologically undermined by refuting evidence. On the other hand, one cannot deny that some practical advise cannot easily be refuted. I have actually heard in a business training seminar this little gem: "If you are doing the right things for long enough, you cannot fail!" (To be instructions.) But one can as short hand for a more specific and refutable set of instructions. People prefer to be able the poor methodology behind such nonrefutable

and will pay for suitable criteria.

cultural practices.efficiently to suggest that functionalism is correct, in the sense that all for example. Some practices are some purpose or other, as championed by Malinowski." sufficient explanation for the practiced on a mistaken theory, and this is sometimes

functionalist explanations of cultural phenomena.
(vi) Economic Rationality.

conjecture will further their interests. But prefer to adopt and spread memes that they contain excessive economic demands, ant people also prefer to adopt memes that do not An opportunity cost of an action is the an economic demand being an opportunity cost. that action (see Alchian, 1968). There highest-valued forsaken option necessary to realize 
opportunities without commensurate reward (e.g., Heaven or Nirvana). Individuals navigate life by (fallibly) weighing and comparing costs and benefits of their actions. These costs and benefits are not only explicitly economic, but psychological and social (egotism and altruism play important roles). People tend to abandon memes whose opportunity costs exceed the benefits.

Economic rationality has surprisingly been overlooked by evolutionary epistemologists until recently, but an organism's adjustment to the realities of resource scarcity relative to its needs is indeed an adaptive cognitive capacity. I see an organism, along with its so-called "subjective states," as belonging to an objective world, and therefore its needs or tastes are objective facts to which the organism adjusts itself. ${ }^{15}$ An exception to the neglect of economic rationality, perhaps, is Wächterhäuser's above-mentioned theory of the origin of the search for information through visual perception in foodacquiring behavior. This theory sees knowledge acquisition as an economic process, but does not link it explicitly to the theory of opportunity cost and marginal utility, etc. Bartley (1990) did work on the connection between the subjectivist economic theory and Popper's theory of objective knowledge, but he did not explore the common evolutionary origin of our appreciation of both non-subjective states of affairs and the opportunity costs of our actions. Radnitzky (1986) also did interesting work on the relationship between economics and epistemology. [Editor's Note 6: See also N. J. Foss, "Realism and Evolutionary Economics" and C. Herrmann-Pillath, "Evolutionary Rationality, 'Homo Economicus,' and the Foundation of Social Order" in the Journal of Social and Evolutionary Systems, 17 (1), 1994.-PL]

The propensity to behave in accord with the theory of marginal utility seems to be quite universal and robust. Experiments have shown that even simple organisms and psychotic people take account of opportunity costs in the way that marginal utility theory suggests. Rapport investigated the microscopic animal, Stentor Coeruleus, an organism without even a recognizable nervous system. When its food was hard to obtain, it made do with second-rate food; and when the cost of the better food was lowered, it would spit out the less preferred food and concentrate on the more preferred. Token economies in psychiatric hospitals show how robust economic rationality is even in cases of extreme mental eccentricity. In token economies, in which patients can earn tokens exchangeable for various goods, the consumption of items varies just as one would expect when prices are raised and lowered. (A lot of work has now been done testing economic theorems in animals-see McKenzie \& Tullock, 1975, ch. 21). There is an obvious evolutionary advantage for a gene that contributes to the propensity of an organism to rationally allocate its scarce resources among its preferences, provided that these preferences are themselves ranked in a genetically advantageous way. I can think of no reason why they would in general not be. ${ }^{16} 1$ mention these studies not to demonstrate or justify the application of the economic rationality assumption beyond financial contexts, but to indicate that such an extension has passed severe critical tests with glowing colors (though Gary Becker has questioned the necessity of the rationality assumption ${ }^{17}$ ). The method of conjecture and refutation obliges me to extend economic theorems to the adoption, spread, and abandonment of memes.

The collapse of the Soviet Union is an obvious case of where, despite 70 years of intense propaganda and repression of alternative memes, the opportunity costs of the attempt to maintain a certain vision of how society ought to be organized became too 
great. Another possible example is the early Kibbutz, which tried to bring about a complete equality between the sexes, and where children were taught the new ways. However, behavioral differences between the males and females spontaneously asserted themselves. The opportunity cost of the experiment-the mothers' lost time with their own children, loss of privacy, etc. - was too great (Spiro, 1979). (One does not have to subscribe to Spiro's explanation to see the point of the illustration).

The classic definition of economics is that of Lord Robbins (An Essay on the Nature and Significance of Economic Science, 1935), which sees economic action as the allocation of given scarce means between competing given ends so as to fulfil as many of an individual's goals (in order of their significance) as possible. This is the notion that seems to cover all organisms, from Stentor to human. Kirzner (1973) has produced a powerful critique of this rather passive account with its exclusive concern with the given. Elaborating Ludwig von Mises' notion of human action, Kirzner points to the entrepreneurial, creative alertness in human action to possible newly worthwhile goals and to possible newly available resources. Thus not only are we humans sensitive to the simple Robbinsian economic realities against which we compare the various memes we encounter, but we are also continually creating and discovering new means and new ends, which must also interfere with any attempt to perpetuate, come-what-may, an uneconomic meme.

(vii) Emotional Rationality: I think that the aspects of rationality described above control our emotions. They help us to make them appropriate to the world as we interpret it, fallibly, through our conjectural theories. This has an obvious link with the problem of the spreadability of a meme (or ideology).

Can intense emotions associated with ideologies make the ideologists irrational and therefore the ideology itself insulated against all criticism? And would the ideology then be more likely to spread? Almost all writers take the irrationality of ideological emotion for granted. Their assumption is that if ideological emotion is thoughtless and therefore independent of theory, then critical argument is irrelevant for it has no target. I grant that intense emotion engendered by an ideology may impair the appreciation of critical argument, but insist that argument is always relevant because our emotions are under the control of our theory of the world and our place in it. They are therefore subject to the rational filters explained above. That our emotions are under the control of our theory of the world and subject to the rational filters makes evolutionary sense, for how else might they be made appropriate to subtle, complex, remote, and even merely hypothetical circumstances? Inappropriate emotions lead organisms to shun the beneficial and embrace the harmful, and as a probable, though not necessary, consequence impair genetic reproduction. Of course, human beings are foolish, but this does not mean that we cannot or are indisposed to correct our errors; it only means that we are fallible and may take
time to readjust our emotions to the facts.

There are two closely associated ideas about the role of emotion and morality in the emergence and spread of ideologies, both of which are of emotion and morality in the ideologies are closed to criticism. One is that ideologies thought to support the idea that emotions, emotions that are not subject to reasonies spring from and thrive on irrational feelings of anger, resentment, envy, greed, etc, unadorned bstract theory or argument: gut emotion and thought are placed in radically different com by abstract ideas. On this theory, held such a theory. Boudon (1989, p. 60) argues that Partments. Pareto seems to have 
rationalizations of feelings, and offers the following as what he conjectures to be the general argument behind Pareto's theory:

1) people believe in the objective truth of all kinds of propositions, both unproved and unprovable;

2) by definition, their conviction cannot be founded on the objective truth of these propositions;

3) therefore it must have its basis in an irrational act of faith;

4) which can only be based on feelings.

The obvious fallacy in this argument is the confusion of objective truth and proof, which (since Gödel) we must always be careful to distinguish. Boudon further argues that both Durkheim (1915) and Weber (1968) also held this sort of theory. He makes a good case that it is implicit in Durkheim's discussion of respect for the flag; but Weber's analysis of respect for charismatic leadership attributes a leader's success to his followers' assessment of his actual performance.

The other idea is that what is most important or even necessary and sufficient in the emergence and spread of ideologies is a high level of agitated, usually violent, emotion evoked by the ideologue in potential followers. Those who espouse this view have in mind the turbulent emotions of the parades and rallies that adorn political regimes and the riots and assassinations that attend their demise. Can the emotions that drive the terrorist to plant a bomb, the protester who goes on hunger-strike, and the Kamikaze pilot all be rational? Surely, one thinks, such emotional people, especially the violent ones, are outside the scope of abstract theory and argument, and therefore of criticism.

But even if ideologies appeal to emotions and passionate moral aspirations, this is no insurmountable obstacle to abstract critical argument. Even the most violent and antiintellectual ideologies are steeped in abstract theory and argument, and their origin and spread is traceable to conspicuously intellectual sources. All the great ideological movements have had rather undramatic beginnings with the writing of an abstract text by some obscure scribbler fascinated by some abstract problem, and they have been sustained or demoralized by abstract argument. [Editor's Note 7: Indeed, arguments in favor of irrationality by philosophers like Nietzsche and Feyerabend are appealing only insofar as they are rationally presented. See my Mind at Large, ch. 2, for more. See also also Percival's section 4.3, subsection (4) below.-PL]

The intellectual content of even anti-intellectual ideologies is no surprise once one realizes that all emotion is cognitive and all cognition is emotional. There is no thoughtless emotion, and no emotionless thought. All thoughts, even of particular things, can only be constructed from abstract ideas and arguments. To suggest that anti-intellectual ideologies arouse people on account of being empty of meaning seems implausible. One might say that meaning is hard to avoid. Even "nonsense" poetry or humor excites us on account of the meaning that we impute to it. Lewis Carroll's "Jabberwocky," for example, contains many words that are not in the dictionary or part of any natural language, yet the poem conjures up in our mind all sorts of strange creatures.

Some writers, such as Durkheim, might say that since at least some emotion is instigated by particular objects, abstract theory is sometimes irrelevant. If this type of emotion were responsible for maintaining ideologies, then they would be immune to 
theoretical attacks against the emotion. However, as indicated earlier, Popper has argued that even the identification of particular objects entails abstract theory that goes beyond the immediate observational data. He writes $(1934 / 1959$, p. 95) that even

The statement, "here is a glass of water" cannot be verified by any observational experience. The reason is that the universals which appear in it cannot be correlated with any specific sense-experience.... By the word "glass," for example, we denote physical bodies which exhibit law-like behaviour, and the same holds for the word "water."

Admittedly, this is a broad notion of theory, but it is, nevertheless, a defensible one. The extension of the notion of theory is parallel to the extension of the notion of information, allowing us to speak of computer programs or genes as containing information. Indeed, just as the concept of information has been extended from its connection with language, Popper's broad notion of theory allows us to conjecture that even a cat and mouse have instinctive theories about each other's law-like behaviour, theories which guide their responses to one another. A corollary is that even if an ideology or some of its components are non-linguistic responses to particular objects, as their emotional elements might be, a theoretical attack may still be appropriate.

My main point is that even if we admit that ideological emotion can sometimes spring from particular objects, this does not by itself make the ideology immune to theoretical criticism. A better example in this context would be the statement "This is my Father." A father is clearly a particular object that arouses much emotion, but it is a particular object that is only understood through a complex and not easily testable theory, a theory that goes far beyond immediate experience. One can easily see how this line of argument can be extended to straightforwardly ideological notions such as "Leader," "Follower," "Heretic," "Class Traitor," etc. Thus theories that ascribe the success of an ideology to a charismatic leader (see Weber) who arouses deep emotions, or to a particular object such as a flag (see Durkheim), cannot exclude the relevance of theory to that propagandistic success. For the theories held by the leader's audience are what make the leader charismatic and what endow the flag with its emotional significance.

Although I argue for the Stoic idea that "men are not moved by things but by the views they take of them" (Epictetus), my position is slightly different, as I argue that the views we have of things are at least partly explained by the way things are. Therefore the way we feel about things is at least partly explained by the way things are. Perhaps closer to my position is that of Dubois: "If we wish to change the sentiments it is necessary before all to modify the idea which has produced them" (quoted by Beck, 1976).

I add that changing a person's theory is not only necessary but sufficient, and moreover is always possible. Hence, abstract critical argument is always relevant. Cognitive therapy. which presupposes that our emotions are controlled by our theories, has passed some empirical tests and is slowly becoming better known. An interesting recent contribution. which details some of these tests, is Good Mood, by the economist Julian Simon (1993).

On the other hand, emotion does have an effect on the spread of an ideology. Therefore, although truth and validity are always relevant, they are not the only relevant factors. Nevertheless, I argue that the effect of emotion on the competitive strength of an ideology can be analyzed in terms of a basic theory of advertising, and that such an
analysis shows how it need not be a barrier to criticism. 
One may distinguish for the purpose of argument between the emergence, maintenance, and abandonment of an ideology. Even if I concede that ideologies spring from and are maintained by non-cognitive emotion, I can still argue that critical argument can prompt the abandonment of any ideology. Maintaining an ideology would then be like the reflex function of the heart which continues until voluntary action may bring it to an end. Some subset of emotions may be like the reflex functions of the body: they will control certain behaviors without conscious thought, but conscious thought can intervene at any moment to override the reflex, just as a coughing reflex might be consciously suppressed out of etiquette at a concert or a formal dinner.

I think that we must concede that intense emotion may impair reasoning, but this does not mean that it eliminates it. Conceding an element of the irrationalist case, I grant that an argument may engender an emotional attitude so intense that some subsequent critical arguments requiring sharp, coherent, complex thought become ineffective. But the proposer of the irrationalist thesis must grant as common observation that intense emotional perturbations cannot last a life-time, though a disposition to such emotions may. Therefore, there will be times when the appreciation of even difficult counterarguments will be unaffected by intense emotion. I also argue that this barrier depends on the correct identification of criticism, which is far from being infallible. One only has to think of trojan horse type arguments.

In pointing to the above genetically evolved propensities to the rational selection of memes, I do not want to deny that the evolution of memes is in some respects independent of genetic fitness. The meme for celibacy, as indicated above, may not serve genetic fitness, but whether and how it is adopted and spread may still be subject to general rational propensities that were selected by evolution because they served genetic fitness for other reasons. Memetic evolution may, as Dawkins suggests, make possible the emergence of a completely new type of self-replicating entity (perhaps computer programs) that even supplants biological evolution.

Less fancifully and more generally, I think we need to endorse Ramsay Steele's (1988) point that to adequately explain the development of human society several different sorts of explanations must be used: (1) genetic influences, (2) natural selection of culture, (3) rational pursuit of goals, and (4) interpersonal invisible-hand processes of the kind studied by economists. My purpose is not the presentation of a complete theory of memetic evolution, but to show the extent to which memetic evolution is constrained by rationality.

Our appreciation of truth, logic, and other rational characteristics has been put in place, as it were, by Darwinian evolution. Once in place, this appreciation acts as a Darwinian-like filter on memes. Moreover, theories and memes in general that satisfy these rational standards are more copyable. To use Dawkins' analogy but invert his suggestion, useful computer programs spread better than computer viruses. There are presumably more copies of Word Perfect than any given computer virus. To point to the numerous instances of erroneous ideas that survive and are reproduced is no refutation, since a Darwinian filter does not have to be $100 \%$ efficient to be effective. Neither do these instances mean that having survived the rational filters once, an erroneous idea will continue to do so. Human beings are fallible, but they can always correct their errors. Boyd and Richerson (1985) conclude from their survey of experiments in behavioral decision theory that: "humans ordinarily make poor judgements" (p. 169). But as Steele (1988, p. 132) puts it: "the question is whether rational choice is an important factor in 
human affairs, not whether it is commonly executed with virtuosic brilliance. $\mathbf{T}$ that people are stupid should not blind us to the fact that they are rational."

\subsection{Objections to An Evolutionary Epistemology}

I cannot ignore certain common objections to the evolutionary epistemology the argument uses. There are three main objections:

1) organisms are imperfectly adapted to their environment;

2) organisms are only adapted to local and temporary conditions;

3) the evolutionary project presupposes what it promises to prove.

Darwin noted many imperfections in the adaptations of organisms to thi environment and these strengthened his case against divine design. A superficial criticin of evolutionary epistemology is that our cognitive apparatus will be similarly imperfoct. O'Hear adopts this approach in his criticism of Munz (1985), saying that the imperfection of adaptation makes it unjustifiable to accord a "positive degree of probability" a "reliability" to the deliverances of our senses. O'Hear is so used to thinking in terms of a justificationist metacontext that he presents other points of view as if they are necessanily justificationist, then criticizes them for not measuring up to these imposed standards. $\mathrm{n}:$ is especially odd when applied to evolutionary epistemologists. All an evolution epistemology needs to conjecture, at a bare minimum, is that:

i) an organism's organs and functions are not completely unadapted, thet organisms can and do know something;

ii) that organisms can correct their errors (a corollary to this is that there are no psychological mechanisms that entrench and perpetuate error come-what-mayt and

iii) that these characteristics have been naturally selected by a real world.

If organisms can correct their errors, then they can move toward greater verisimilitude. There is no need to introduce the notions of reliability or positive degrees of probabilit.

Critics have said that since organisms are adapted only to local and temporan? conditions, how can the evolutionary process issue in a universally legitimate cognitive apparatus? The answer to this, I think, is that organisms are indeed adapted in som respects to relatively local and temporary conditions, but that they are also adapted to stable features of the environment and also to law-like regularities of the piorld. Mlost multi-cellular organisms, for example, are adapted to gravity. Organisms can also be adapted to ranges of variation in their environment. The evolution of what Emst Matr calls "open programs" takes account of the variability of local conditions. An open program is a genetic cognitive mechanism that can acquire information not contained in the genome and store it. Examples are the genetic capacities for Pavlovian and operant conditioning. (Admittedly, there are species specific ranges of capacity in operant and classical conditioning, as Seligman \& Hager, 1972, note, but this only shows that organisms are not perfect cognizers. My point is to put the local adaptation criticism in perspertive. 
Indeed, the genetic coding of general values. such as truth and consistency, is partly an evolutionary solution to the problem of changing circumstances.

The third criticism of an evolutionary approach is the Pyrrhonian sceptical rejection of the whole enterprise as presupposing what it is trying to prove. Again this criticism draws its strength only from a justificationist metacontext. Only if one assumes that we are trying to prove or probabilify the deliverances of our cognitive apparatus does the sceptic's taunt have any sting. In fact, good (supporting, favorable, positive) reasons are impossible, useless, and unnecessary for rational thought (see Miller, 1982, 1994). Popper, I think, is right to say that the sceptic's position can never be logically refuted, but is the sceptic's impregnability worth the price? Sceptics simply deprive themselves of the explanatory power of evolutionary theory. We conjecture that we can know and correct our errors and then we explain this by the theory of evolution and the postulation of an independent reality; we do not justify the conjecture, we only explain it. There might be other possible explanations, but there are no strong candidates. O'Hear (1988, p. 83) suggests an evil demon as a possible explanation, but this is rather weak as it is simply tailored to the facts; whereas the theory of evolution combined with a hypothetical realism can make interesting and testable predictions. If one asks the sceptic why genes that structure organisms to assume that there is an independent reality have an evolutionary advantage over those genes that do not, the sceptic has no answer. The evolutionary epistemologist, however, does have an answer: because there is indeed an independent reality (with the following structure...). If one asks me why realism has higher copyability, my answer is that realism is true, and accords with our genetically evolved preference for the truth, which in turn is produced because realism is true.

\subsection{The Logic of the Propagandist's Situation}

Let us now take a further look at the logic of the situation facing the propagandist, whose goal is the maximum spread of a doctrine at minimum cost in terms of intentional and unintentional error in its replication. The propagandist's message is introduced into a world already populated by other memes that take up some of the limited processing capacity of human brains. and is thus immediately in competition with rival memes. The propaganda, the doctrine itself, is an autonomous objective product that has properties that transcend the propagandist's understanding and thus complete control. These properties are the intinite ranges of logical and information content, as explained above. The information content is of particular concern because, since it is the class of all those statements that are incompatible with the doctrine, it contains all the theory's potential criticism. The propagandist. therefore. cannot foresee and prepare for all potential criticism. But I want to stress that insofar as the doctrine is an object with these autonomous logical properties, making copies of it is a logical task. A major weakness in Dawkins" position is the neglect of this -World $3^{-1}$ character of memes; it thus overlooks the interactions between the physical embodiments of the meme, the beliefs, and the World 3 object to which they correspond.

As a corollary of this. Dawkins. like most theorists, overlooks the importance of abiding by truth and logic in the reproduction of memes. One might suspect from Dawkins" cocount that the truth or validity of a meme were a hindrance to its reproduction; in fact they enhance a doctrine's copyability. They enhance the learning, memory, recall, and 
transmission of memes from brain to brain. IEditor's Note 8: Thus, Jacques Ellul's fo observation in Propagandes, 1962, that education and literacy increase the vulnerentan of the mind to propaganda. - PL.I Most theorists think that the propagandist's probly is a matter simply of psychology and sociology --into which logic, quite a different sution does not enter. (This, I think, is partly due to over-specialization in academia and creation of exclusive departments for administrative purposes.) But actually propagandist's problem is also one of logic: the most effective propagandist will be who becomes a connoisseur of the logic of the propagandistic doctrine and its rivals.

In a well known passage on rhetoric in the Phaedrus, Socrates poses the quetion "Well, if a speech is to be classed as excellent, does not that presuppose knowlede of the truth about the subject of the speech in the mind of the speaker? [Penguin odition 1988, p. 71]" Phaedrus answers with what is now the common view: "But I have ben told, my dear Socrates, that what a budding orator needs to know is not what is rean right, but what is likely to seem right in the eyes of the mass of people who are going to pass judgement: not what is really good or fine but what will seem so; and that it is this rather than truth that produces conviction [p. 71]." Socrates' response to Phadrus is that even a speaker who wishes to mislead will be successful only insofar as the speaker is not misled. Socrates's argument for this is that misleading someone about reality requirs small steps away from reality, for slight differences between things are the most misleading Hence the deceiver must know the true state of affairs in order to recognize the small steps from reality to the false position. (To return to the computer virus analog: as Dawkins points out, a computer virus whose effects are too obvious may do a lot of damaze but will be short-lived.) Thus the logic of the propagandist's situation (or of the carrier of the meme) would seem to demand cultivation of an interest in the truth.

The situational logic of even a mendacious propagandist demands cultivating a healthy interest at least in opponents' theories, in order to judge their distance apar. There is an incentive for propagandists to learn the criticism of the propaganda, for an opponents criticism provides excellent clues about how propagandists see their own theory. what the! would regard as a large distance between theories and a small distance between theorix. The presence of alternative systems of belief in ancient China led to the explicit analisis of argument by the Sophists and Mohists.

Dawkins (1982) develops the idea of an arms race in gene evolution: as prey become incrementally more adept at escape and avoidance, so predators become incrementalls: more adept at predation, which in turn spurs further improvements in the defense mechanisms of prey. The evolution of the explicit analysis of argument in the Mohist and Sophists may thus illustrate a further analogy between memes and genes.

Suppose we are comparing two propagandists (meme replicators): one who intends to spread an erroneous doctrine by deception and sophistry and one who intends to spreac a non-erroneous doctrine by sound argument. Why should truth and validity help to spread the latter doctrine? My answer is that truth and logic help us to learn, remember. and recall information, act as criteria of faithful reproduction, provide the tools for the application of the doctrine to problems, and the tools for criticizing competing doctrines We can enumerate the elements of my answer as follows:

1. Socrates neglected an important ally of truth and validity in rhetoric: mnemonia Reality itself acts as a mnemonic, constantly reminding us of the truth. Henor 
a true doctrine will not only remind us of itself through being consistent with all our other truthful or truth-like observations of the world, but we shall also be reminded of the doctrine by those observations that are implied by the doctrine alone or in combination with other true assumptions we have about the world.

2. The validity of an argument or the consistency of a theory helps us to understand, learn, and recall it. Experiments have shown that learning and recall are most efficient when the items to be learned or recalled are organized according to a schema imposed by the subject, and the more familiar this schema the better it is in facilitating memory. Logic itself is such a schema.

3. Indeed our learning and understanding of language itself is dependent on a grasp of logic and the ability to impose this schema on the tools of language. I know the meaning of the word "red" if and only if the set of objects to which I take it as representing is exclusive of the set of objects to which I take "not red" as representing and that these two sets are jointly exhaustive of all objects in the universe. (The same point can be carried through even if one confines oneself to relevant categories.) This is only possible if I abide by the law of contradiction and the law of the excluded middle. For suppose the sets were not exclusive: then there would be an object that I took to be both red and not red, violating the law of contradiction. If there were an object that lay outside these two sets, then there would be an object which I took to be neither "red" nor "not red," violating the law of excluded middle. Expressed more simply, in teaching a child the meaning of a word, one must be able to systematically affirm the correct use and deny the incorrect use. The same point applies to the transmission of any word and therefore of any system containing sentences.

Actually, for reasons explained by Hattiangadi (1987), no two people have exactly the same meaning or theory. To copy what someone else believes is a theoretical task and is therefore conjectural. What normally happens is that there is sufficient overlap in accepted meaning between two people for them to be able to communicate. Applying this to the evolution of memes, one can see that a sufficient number of accumulated incremental deviations, perhaps over generations, could lead to very different and incompatible memes.

Dawkins overlooks these sorts of points because he tends to see the copying of memes as rather like photocopying, but in photocopying accumulated deviations (known as noise in engineering terminology) lead to a loss of meaning. On the other hand, Dawkins is aware that different people interpret the same theory in a different way, taking bits from the original and combining them with ideas from elsewhere, and wrongly thinks this poses the threat that memes might not be discrete like genes but instead subject to blending and continuous variation. His solution is to define the meme as what the various interpretations of a theory by different thinkers have in common (Dawkins, 1976, p. 196). But he need not have resorted to such a formulation just for this alleged problem, since we already know that propositions, which is what people believe, are discrete-at least for any particular language. ${ }^{18}$ Compound propositions can be broken down into simpler propositions and a theory may be analyzed into its infinite information content, but these units are discrete. Incidentally, the infinite size of a theory's information content is what can give the impression of blending and continuous variation. 
4. Doctrines that scorn logic or even hold its violation to be a virtue (Tertullian's creed of Hegel's dialectic) nevertheless depend on the of logic for their faithful replication. How else can a faithful distinguished from a heretical variation if there is no recourse to the law
contradiction and modus tollens? 'lo establish what is logically compatible
incompatible can be very difficult. This can only be done by the incompatible can be very difficult. This can only be done by the creative difficult than constructing the theory itself. Absolute contempt of logic is mon bluff or confusion. It is like an arrogant creator of computer viruses is mete to be above the operating principles of computers. No matter how much a criming one is. one has to work within the constraints of one's medium. An absurd doctrine under assault may gain temporary protection from an obfuscaton neglect of logic, but this will cost dearly in terms of its faithful reproduction.

There is a trade-off between fecundity and fidelity of replication. A contradicton doctrine, or other neglect of logic, will produce many offspring, but fidelity will decline My personal experience is that people who adhere to such systems make a virtue out of the fact that their ideas change. As I explained above, if we see memes as instruments that people use to get what they want and thus have background assumptions necessan for their use and imitation, then inconsistency of these assumptions will impair the background of the meme. Any imitation of a meme requires an understanding of these

interpretations, and memes, may be the result.

by drawing out in explicul but necessary in making the most of our stock of knowledge the achievement of Euclid's Elements. Many recondite content of theories. Just think of can sometimes be logically inferred. Many surprising and even wonderful conclusions classes is a case in point. Withouted from initially trivial premises. Russell's paradox of of ideas cannot be applied to the ever a political theory, religion, or other popular sistem But capacity to solve problems is why the syging particular problems facing the adherents to apply the system logically would system was adopted in the first place. Pretending competing ideas.

\subsection{Insulating a Meme from Criticism Impairs its Copvability}

Insulating a meme from criticism is presumably the analog of making a computer might reply that on the paradoxically, trying to save a doctrine can destroy it. Dawkins to take place in any case-that some model we would expect some mutation of memo but my point is the less obvious one: memes would lose their content whatever we donot only fail to prevent mutation frat active attempts to save a meme from criticism take place, but actually promote it. Making place, not only simply allow mutation to its copyability by approximating the cover, I wish to argue that a meme can enhanir imitation, clarity, objective specifiability, and pubtic of a scientific theory. For ease of 
but these same characteristics are held by Dawkins to be a detriment to both computer viruses and mind-viruses. This is because, again, one of the main weaknesses of Dawkins' model is his neglect of the World 3 characteristics of memes.

Dawkins points out that the same three characteristics that make for high survivability in genes must be the same for memes: longevity, fecundity, and copying-fidelity (1976, p. 194). In other words, the longer a meme exists, the higher the rate and precision with which copies are made, and the greater the chance that copies of the meme will exist in the future.

We can usefully interpret the alleged propagandistic advantage conferred on a meme by insulating it from detection and criticism in terms of Dawkins' model. Any such insulation would have to operate by enhancing the meme's longevity, its fecundity, its copying fidelity, or a combination of these. Hiding a doctrine as a "mind virus" is surely going to save it from criticism but at the cost of making it hard to copy and spread outside the initiated. Perhaps this is what happened to the Gnostics' "secret knowledge," only available to the initiated. In contrast, Gibbon (1776, p. 147) attributes the propagational success of Christianity to the fact that it threw off the fetters of the Jewish religion, which kept the teachings and promise of salvation confined to the descendants of Abraham. If there are hidden "mind viruses," then they would be like unspecifiable crafts. Such crafts cannot be passed on by prescription, since no prescription exists. Since they can only be passed on by example from master to apprentice, their rate and range of diffusion is greatly restricted. If the craft falls into disuse for a only generation, it will almost certainly be lost.

Immunizing a doctrine from criticism either revises the doctrine and hence abandons it, or encumbers it with extra theoretical baggage, or both. In either case copyability is compromised. To take a trivial example, one may have the theory that all bread nourishes, but then find that a certain batch actually killed those who ate it. One might not regard this as a refutation, but instead say, well, that is not what I meant by "bread"; or one might say all bread nourishes except this particular batch. One can imagine a long series of counter-examples that lead to a corresponding series of qualifying subclauses. Each modification is treated as insignificant, but the unintended effect of an accumulation of individually insignificant withdrawals is that the original theory (meme) is abandoned. Increasingly cluttered with clauses dealing with exceptions, the successive replacements also become more prone to copying error.

In analyzing the effect of "immunizing stratagems" on the evolution of a meme, one must guard against dismissing each evasive move as an insignificant modification, while the "essence" of the meme survives. (Gregory, 1987, p. 254, makes this mistake in his entry for "falsification," also confusing the acceptance of a refutation and abandoning the refuted theory. ${ }^{19}$ There are at least three points here to note:

1) one thing we learn from Darwin is that a significant number of individually insignificant changes can lead to colossal change;

2) one thing we learn from logic and mathematics is that even a small change in a set of assumptions can lead to radically new ranges of implications and ramifications;

3) one thing we learn from chaos theory is that two hypotheses that differ very little can have consequences very far apart. 
Further, Lakatos' (1970) distinction between a sustainable "core theory" "auxiliary assumptions" cannot fully rescue this idea. One might at first think that are two main ways in which a theory $T$ may be immunized through changes in assumptions of the theory: (i) a move from $T$ to $T^{\prime}$ (where $T^{\prime}$ is the conjunction of $T$ one or more auxiliary assumptions, denoted by $B$ ); (ii) a move from $T$ to $X$ (where $X$ is $T$ minus some of its assumptions, perhaps with replacements). Only (ii) represents the abandonment of assumptions of $T$, and its replacement by another theory. One migh argue that (i) preserves the original theory within the substitute, and therefor immunization can preserve a meme. Thus Lakatos (p. 175) says: "For instance, we may have a conjecture, have it refuted and then rescued by an auxiliary hypothesis which not ad hoc in the senses which we have earlier discussed. It may predict novel facts some of which may even be corroborated." But (i) is not a logically possible immunization. The modified theory cannot be consistent with the falsifying evidence if one simply adds extre assumptions that increase information content. For suppose theory $T$ is false with respect to evidence $e$; then, since a conjunction is false if and only if one of its conjuncts is false any conjunction consisting of $T$ and an extra assumption $B$ will also be false with respect to $e$.

Actually, Lakatos was more careful elsewhere to distinguish different components of a theory. But this confusion is quite common-and others are less careful. Boudon (1989, p. 161) makes a similar mistake. If one distinguishes between a core theory and its auxiliary assumptions, then one must note that the core theory in Lakatos' case can only be saved and still contribute to explaining the facts by replacing one or more of the auxiliary assumptions by one or more new auxiliary assumptions. In such a case one might say that the core theory has been saved at the expense of the auxiliary assumptions. But such auxiliary assumptions are not always possible. Notwithstanding the Quine/Duhem thesis, which states that any recalcitrant evidence can be deflected away from a privileged sector of assumptions by drastic enough revision elsewhere in our theoretical system, no one has produced a proof that such assumptions are always possible (see my Openness to Argument). Some Newtonians tried for 50 years to explain the perihelion of Mercury with the standard Newtonian theory and failed. This at least shows that humans have a finite capacity for immunizing their theories.

We should now be clear that "protective measures" reduce the fidelity, fecundity, and longevity of the meme. Indeed, the more drastic the "protective" measures, the more destructive they are of copyability. In the case of Tertullian's creed, this protective device, if taken seriously, actually empties Christian doctrine of any content since it tolerates devises," both Marxism and contradiction and the incremental accumulation of "protective meaning and have been encuristianity have become emptied of much of their distinctive Wells, 1988; on Marxism, see Steed with excess theoretical armor. (On Christianity, see Marxism have high fecundity but 1992.) So today one can say that Christianity and contradictory systems. of the Quine/Duhem thesis the toleration of contradictions tell us about the relevance assumption faces the tribun copyability? The Quine/Duhem thesis suggests that no of other assumptions, and that experience singularly, but rather as part of a network 
observations. Quine suggested, as a hypothetical example, that one could reject even the law of the excluded middle or the law of non-contradiction to save a favored assumption against awkward evidence. But if one protects a privileged sector of one's assumptions from recalcitrant evidence by so drastic an action as repudiating the law of noncontradiction, one will almost certainly empty the theory of content and give full reign to copying error, since one cannot deny of any system prompted by the first that it is not the "true faith."

A possible reply might be based on the work of Avron (1990). Building on Laporic \& Da Costa's invention of paraconsistent logic (1984), Avron has constructed a paraconsistent logic that incorporates relevance logic. His idea is to confine the implications of a contradiction within the same category of statements. This, he argues, is what humans do naturally. An unnoticed contradiction in one's thought about covalent bonding would not lead one to any conclusions about which wine your wife would like with her meal. However, as Goertzel (1993) points out, partitioning of statements is arbitrary. To give Avron a run for his money, one might avoid arbitrary partitioning by tying up each category of statement to a category of problem. But this would fail to capture the life of scientific debate and progress, which involves unforeseeable cross-fertilization of different disciplines. In science, the correlation of statement categories with problem categories is continually changing. But partitioning would actually freeze these correlations and thus exclude cross-fertilization. For example, Hamilton (biologist) (1981) could not have used the work of Axelrod (political scientist) on the prisoner's dilemma to explain the evolution of cooperation in bacteria and other biological systems. This is clear in the case of science, but it is a general point.

I must say something about the simple immunizing stratagem of just denying the evidence. I deal with this more adequately in my doctoral thesis (1991), but put roughly my argument there is that if all possible counter-evidence is systematically denied, then all the empirical content of the theory has been jettisoned and we are dealing with quite a different theory. What has been saved is face, not theory. Moreover, as is clear from Festinger's work described above, this method of deflecting counter-evidence is difficult to sustain psychologically.

To recapitulate, Dawkins says that memes, like genes, have higher copyability if they are high on fidelity, fecundity, and longevity. But "immunizing stratagems" (Popper, 1943) or "mind virus" protectors, ad hoc hypotheses, and reinforced dogmatisms-such as the contempt of logic-actually impair these qualities. They do this by either abandoning the meme, encumbering it with excess "protective" armor, or generating uncontrollable factions as different would-be faithful individuals work out different "true" meanings from the contradictory doctrine supplied.

Applying Dawkins' model in ways that he has overlooked, we can also see here a partial explanation for the successful spread of science and other systems that share certain of its features. A very general theory using only few premises clearly has more copying fidelity, since there are less distinct items to learn, recall, and transmit. Being general, it has greater fecundity, since it lends itself to application on many different problems at the same time. The theory of levers, for example, has many copies partly because of its infinite range of application. Arguably, the theory has greater longevity because there is less danger of its parts being separated, and even if separated, easily re-combined. A loose collection of less general rules of thumb dealing with different domains would be more 
prone to separation. Perhaps the key memes here are the methods and attitudes Marxism and monotheistic religions spread well initially because they resembled claiming to offer comprehensive explanatory theories with relatively few premimes

\section{Wishful and Fearful Thinking}

In failing to look at the logic of the situation facing our ancestors (plus the variants succumbed to it), Dawkins falls into the error of assuming that humans can be immune (or impervious) to evidence and argument.

In applying his general position to religion, Dawkins attempts to show that the meme of heaven and hell are self-perpetuating, and also that blind faith is possible. Dawkin' account portrays religion as more rigid than it is. First the argument that heaven and hell are self perpetuating: "The idea of hell fire is, quite simply, self perpetuating, because of its own deep psychological impact. It has become linked with the god meme because the two reinforce each other, and assist each other's survival in the meme pool" (1993, p. 198). Dawkins attributes the perpetuation of the hell fire meme to an unanalyzed "psychological impact." This does not allow us to explore the degree to which the adoption and spread of this meme is open to argument and counter-evidence in general.

A Darwinian analysis of wishful and fearful thinking, however, allows us to explain the "impact" of the hell fire and god meme. I will argue that wishful and fearful thinking evolved because they contribute to an organism's goal-seeking behavior. If we acknowledge the Popperian point that an organism's expectations, beliefs, and perceptions are active exploratory hypotheses, we can then see wishful thinking as a conjecture that maintains an organism's persistence towards its goal in the face of possibly misleading evidence, and enables the organism to weigh possible counter-evidence according to the values at stake. Unlike Freud (1911), who separates the mechanisms of wish generation (the Id) and reality testing (the Ego), I argue that wishes are theory impregnated and are active explorations can help organisms attain their. (I owe the initial insight that wishful and fearful thinking Popperian elaboration is my work.)

Other theorists, such as Elster (19

cases in which wishful thinking has (1982) and Pears (1984), typically argue from plausible that wishful thinking systematically leads error and its perpetuation to the non-sequitur irrational. But I argue that the epistemolo error and its perpetuation, and is therefore of these theorists is compounded by theirogical situation is far more subtle. The mistake of rationality, which would lead them to adherence to impossible justificationist standards

In the efficient pursuit of them to see irrationality anywhere.

to it. Since it is fallible and mostly ignoal, an organism must discover the possibilities open Now its ignorance is literally infinite, so the of the world, it must explore some hypotheses. to test. To pick hypotheses without any core an infinite number of possible hypotheses more efficient than failing to pick any constraints would be inefficient-though clearly hypotheses? Clearly, an evolutionary advan it eliminate some (i.e., some ranges) of these all or even some ranges of hypotheses irrelage would ensue if the organism could eliminate to have brought this about. As Katz (1937) puant to the pursuit of its goals. Evolution seems into edible and inedible things. An animal put it: "A hungry animal divides the environment 
More accurately, the animal divides its environment into areas worth testing for food or escape. This narrowing of the range of hypotheses to be tested can be thought of as itself a higher level conjecture and the product of millions of years of evolution. It is also an open program in Mayr's sense. (On the idea of a hierarchy of evolved conjectural cognitive mechanisms with selective test-ranges see Campbell, 1960.) Thus we have a tendency in the course of evolution for the organism's beliefs to be related to its interests. Could this relationship have been brought still closer?

We are still taking for granted Dawkins' view that humans are creatures of Darwinian evolution. Very desirable or fearful possibilities are worth testing for. Organisms that did not test for very desirable or fearful possibilities would tend to have been eliminated in favor of our more opportunistic and circumspect ancestors. (I assume that evolution had already made desires and fears fairly well correlated with reproductive needs, though I should add that the correlation need not be exact for the purposes of this explanation.) I am not suggesting that all organisms will display the same level of exploratory behavior as a scientist. The precessionary caterpillar is an interesting case. One can put a string of these caterpillars round the edge of a plate and their favorite food, pine needles, in the center. They will follow each other for days and starve to death. Some behaviors exquisitely adapted to certain eco-niches will be disastrous in others because not all organisms have the capacity to vary their behavior sufficiently.

Human wishful imagination, however, helps us to escape from the edge of the plate. This is consistent with Lorenz's sequence of increasingly flexible and open behavioral programs, from kinesis and phobis at one end of the phylogenetic continuum to association, imitation, insight, and playful exploration and conscious human action at the other end. There is a rough reflection of this sequence in the phylogenetic order leading to homo sapiens sapiens.

Admittedly, science does not operate with beliefs, but instead with objectively stated hypotheses-but the same epistemological and methodological considerations apply to any cognitive system, let alone any organism, exploring its world. Yet in order for a possibility to be tested by our pre-linguistic ancestors, a relevant belief had first to be generated. Organisms are not passive recipients of information, but active explorers of the world. For those unhappy with the idea that our pre-linguistic ancestors had beliefs, one can substitute either a protolanguage-as per Hattiangadi, 1987--or the evolutionary biologist's term "strategy," which covers all functionally significant behavior that occurs if and only if certain conditions are fulfilled, something that even bacteria seem to havesee Hamilton \& Axelrod, 1981. But as Steele points out in a personal communication, the extension of the word "theory" to animals is no greater leap of analogy than the extension of the word "information" to stretches of chromosomes-genes.

Moreover, the more desirable or fearful the possibility the more testing it is worth; hence for best results the belief had sometimes to be retained in the presence of (some) counter-evidence. I assume here with Popper that all organisms-indeed, all knowledge acquiring systems-are fallible. That means that organisms can be wrong not only in their initial hypotheses but also in their interpretations of their exploratory tests. Even the results of observational tests in a well controlled laboratory are provisional, and are sometimes worth re-testing, in the course of which even very careful observations are sometimes rejected (Popper, 1934). 
I think that these epistemological and methodological constraints, ectio evolutionary pressures, explain the psychological fact, noted by Popper (1972), absolute certainty does not exist, and that if the stakes are high enough one may tex trivial assumptions. I Editor's Note 9: I would connect this lack of certainty with someth even more fundamental than epistemological constraints: to wit, the noise endemic to energy exchanges, including informational, in the cosmos. $P L]$

With my hands in my pockets, I am quite certain that I have five fingers on hand; but if the life of my friend depended on this being true, I would take them of my pocket to check. The certainty of a belief, therefore, can always be improved upon Hence no belief, no matter how "certain," can be absolutely compelling. Beliefs the concern very valuable things are often for this reason difficult to dislodge for examph "irrational" jealousy, beliefs in ghosts of lost relatives, belief in a world of superabundanes etc.

I have argued that natural selection working on organisms subject to certain generd epistemological and methodological considerations can be expected to produce organism that have a tendency to wishful and fearful thinking, which can maintain belief in the presence of counter-evidence. However, repeated refutations can and do undermite apparently absolutely stubborn beliefs. Without an obvious alternative, an animal my explore the possibilities of a hiding place or escape route several times but will tend to abandon it if it is ineffective. Even passionately held religious systems of ideas can succumb psychologically and sociologically to empirical refutation. Festinger, in his book When Prophecy Fails (1956), supplies many examples.

On the surface, Festinger's work seems contrary to my own, but it is in fact in complete agreement with my thesis. Festinger attempted to show that groups highly committed to an idea will often increase their efforts to convince others after a disconfirmation of their beliefs. They realize the inconsistency between their belief and their observations, and are trying desperately to resolve the dissonance. Those who have heard of Festinger remember this point and it is often adduced as evidence of human irrationality. However, they rarely seem to remember that Festinger goes on to show that with further disconfirmation morale drops and the movement disintegrates. As Festinger points out, the details of the messianic movements he comments on are poorly recorded. However, two of the groups that he deals with, the Millerites and the Sabbataians, although at first increasing their proselytizing after initial disconfirmation, disintegrated after repeated disconfirmation. Thus, "the Sabbataian movement strikingly illustrates the phenomenon we are concerned with: when people are committed to a belief and a course of action, clear disconfirming evidence may simply result in deepened conviction and increased proselytizing. But there does seem to be a point at which the disconfirming evidence has mounted sufficiently to cause the belief to be rejected" (Festinger, Rieken \& Schachter, 1956, p. 12). A similar fate characterizes the Millerites. Significantly, many of the adherents had sacrificed all their property, and so in Dawkins' eyes had strong reason to irrationally hold on to their
wishful belief.

This analysis of wishful and fearful thinking is useful if we are to take account of the stubbornness of some systems of ideas. There is an important element of truth in Dawkins' idea that the most successful "mind-viruses" will be those that produce unshakeable beliefs. However, by placing beliefs in the context of an evolutionary view of humanity, we are also in a better position to see that wishful and fearful thinking are 
no guarantee against criticism, but in fact are ways of making the most of criticism in the pursuit of some goal. For the stubbornness with respect to criticism is not absolute, but proportional to the importance of the values at stake.

Denise Meyerson is one writer who acknowledges the value of a degree of conservatism towards our beliefs in the face of counter-evidence, but who still thinks that ideological stubbornness is absolute. She fails to consider the possibility that the degree of conservatism may be proportionate to the degree of importance of the issue; stubbornness for Meyerson exists in only two discrete states: reasonable or absolute. Meyerson asserts that there is a difference between a scientist's "charitable" protective attitude to a theory's predictive failures and the digging-in that acceptance of an ideology involves, which is maintained "come-what-may" $(1991$, p. 61). On my analysis, we ought not be surprised that a scientist's defense of a possibly refuted theory whose truth or falsity has little emotional significance is relatively less stubborn than the ideologist's defense of a theory whose truth or falsity has great emotional significance. We cannot conclude that the defense of the latter is come-what-may, and Meyerson furnishes us with no general argument that this defense should be absolutely stubborn. Of course, methodologically one ought to positively look for sound criticism, and one might out of fearful thinking avoid what one suspects to be counter-evidence. Following Pears, Meyerson thinks that she has obviated the paradox of self-deception, convincing oneself of a belief that one contradicts, by using the word "suspicion" rather than belief (p. 65). One only suspects that there may be counter-evidence, without actually believing that there is.

But this seems to be a verbal slight of hand. Suspicion seems to be weak belief, rather than no belief at all. Now the strength of a belief may be indicated by how much a person is willing to sacrifice in action based on it, and all action is based on belief, whether weak or strong. Hence Meyerson's fearful avoiders of counter-evidence must be willing to make some sacrifice to avoid the possible counter-evidence. But then their "suspicion" must amount to some belief, to wit, that they actually doubt their cherished belief. We also need to note that we cannot easily avoid surmising that people who are fearful of the truth understand that belief may be involuntarily undermined by the evidence despite their wishes to the contrary.

But is this weakened belief at least guaranteed against undermining counter-evidence? No, for even our most fervent desire or fear cannot act infallibly to exclude from our view all possible counter-evidence, because in order to do this one would have to survey the infinite information content of one's view, and this is impossible. Thus, according to my analysis, the belief may still be discarded in response to the right argument, whether looked for or not.

The major weakness in Meyerson's case is that she overlooks the evolutionary origin of our psychological make-up. As a consequence, she feels free to postulate absolutely stubborn beliefs generated by wishful thinking, just as a science-fiction writer unconstrained by physics feels free to postulate ants the size of houses. Like most writers who ignore our evolutionary origins, Meyerson assumes that the way we deal with counterevidence is tailored to our desire for contentment or a life free from doubt and uncertainty. However, what serves the reproduction of our genes may not coincide with what serves contentment or the attainment of absolute certainty. According to the gene-centered view of biological evolution, the emotions we have are those that have enhanced the copyability of the genes that construct brains capable of having them. In other words, what maximizes 
the reproduction of genes may not maximize the attainment of contentment; our evol mechanisms for registering error may wake us rather unpleasantly from our fantasy of wishful thoughts.

To recapitulate briefly, humans engage in fearful and wishful thinking important possibilities. This tendency has evolved because it contributes to attainment. Admittedly, the "hell fire," "heaven," and "god" meme as such did not en genetically, but we may conjecture that they arouse tenacious beliefs because of genetin evolved wishful and fearful thinking.

\section{Blind Faith is a Myth}

As Festinger has shown, even passionately held religions to which people have sactifi their worldly goods succumb to counter-evidence and are ipso facto not blind faithe.

Being without an evolutionary analysis of fearful and wishful thinking, Dawh (1976, p. 198) finds blind faith easy to believe in:

Another member of the religious meme complex is called faith. It means blind trust, in the absence of evidence, even in the teeth of evidence... The meme for blind faith secures it own perpetuation by the simple unconscious expedient of discouraging rational enquiry.

Strictly, what Dawkins says is not incompatible with my thesis, but its inaccuracy makes it very misleading at best. In saying that beliefs are sustained in the presence of counter-evidence, Dawkins commits no error, but in failing to qualify this statement, ox can only infer that his intention is to say that the beliefs would be sustained come what may. But as we saw, this would not make evolutionary sense. Evolutionary theory suggests that there must be some responsiveness to argument or counter-evidence. Beliefs cannot be blind. At least, one cannot argue that so-called blind beliefs are blind because of some psychological absolute certainty, since the existence of such certainty is undermined by self reflection.

Dawkins has confused two senses of being closed to argument. Clearly, one can follow a life-style that would reduce encounters with counter-evidence to one's beliefs. This is one sense of being closed to argument. But there still remains the question whether the human mind can be completely closed to evidence that has gotten past the dogmatic lift style. Dawkins supplies no answer to this question. As I have already pointed out, hiding a doctrine will impair its copyability; a propagandist's lifestyle must involve presenting the meme to others and hence always run the risk of encountering possibly undermining
criticism.

There is another problem with countenancing the existence of blind faith. As Dawkins says, the survivability of a meme depends, among other things, on its competition with other memes for embodiment in people's beliefs. If blind faith really existed, then the first providing it replicated quickly have completely dominated all minds capable of it. emerged and "infected" pristine mindsh before any rival memes exploiting blind faith if there had been more than minds. There would now be only one religion. And even But since there are many relige, there would be no conversions from one to another. 
factions in any one religion, one cannot easily maintain the picture that Dawkins paints. Dawkins can hardly claim that most of the conversions and factions are produced by errors in meme replication alone. The same points can be made about any sort of system of ideas: political, economic. sicial. etc.

Dawkins admits that not every child adopts the religion of its parents, but he asserts that here the child has been exposed to a particularly potent infective agent--... a Wesley or a Jim Jones, or a St. Paul. But this is an admission that the first faith was not blind. Or is Daukins himself using an immunizing stratagem, since he has defined "more potent infective agent" simply in terms of the fact that the relevant meme is substituted for a rival. No matter how common conversions from one religion to another, Dawkins could always say that they were produced by the arrival on the scene of more potent infective agents. In other words, blind faith exists until it is no longer blind. And the only way we know whether it is blind or not is whether it is retained or not - a a theory of little content. If Dawkins theory has any content at all, it implies that conversion from one religion to another is a one way street-from the less to the more virulent mind-viruses. But the evidence is that there is a great deal of reversion to previous beliefs. Closer investigation of apparently unchanging ideological or religious movements reveals that their membership is in great flux. with people joining and others leaving the movement. Barker (1988, p. 167) reports that in her study of the Unification Church she found that at least $61 \%$ of those who joined the movement during a four month period in 1978 had left within two and a half years. Others have found very similar voluntary defection rates. ${ }^{20}$ One way these facts can be taken into account by a Dawkinsian is to accept that people are rational and correct their own errors (mind-virus infections), but that erroneous memes may be perpetually transmitted provided the rate at which people leave a movement does not exceed the rate at which people join.

\section{Conclusion}

Dawkins theory of memes has many virtues, especially the analysis of what makes for high copvability, but the account lacks an explanation of the interaction between logic, psychology: and genetic evolution (or World 3 object generally). In his enthusiasm to show how memetic evolution can be independent of genetic evolution, Dawkins has overlooked some relationships that can explain the fluidity of ideological organizations. When we look at the interaction of genetics. psychology, the situational logic of the meme propagator, and World 3 objects, we discover interesting relationships between rationality and copsability.

Although focusing on Dawkins' theory of mind viruses, I have encroached on a very large problem that I have found exceedingly difficult to deal with in the confines of a single article. Nevertheless. I have tried to bring together some disparate areas. The conneting thread is the Darwinian evolutionary perspective. In both phylogeny and ontogeny. we have found that rationality is a powerful influence at all stages of the variation, selection. and reproduction of memes. World 3 objects and relations are relevant not only to the potential logical criticism of memes but also to their copyability.

The stubbornness we see in religions, and which so impresses Dawkins, is due, I think, to uishful and fearful thinking. a propensity to hold on with greater tenacity to what is 
regarded as important, only giving up the belief after repeated refutations. But is part of the rational process in humans--not something outside of it.

Useful programs generally spread better than computer viruses. Likewise, other being equal, problem-solving, logical, true, informative, economic, and well ong ideas spread better than useless, illogical, false, uninformative, badly organized Contrary to Dawkins, mind-viruses succeed to the extent that they partake of the for not the latter, characteristics.

\section{Notes}

1. I say propensities because the word "mechanism" on its own suggests the now nf and defunct determinism of 19 th century science. The processes of variation, selection, reproduction operate according to weighted propensities in Popper's (1990) sense.

2. As Steele points out, even if humans began to control their own evolution by engineering and artificial selection, they would still also be subject to the natural selection of th genetically fit. Then an adequate explanation would have to combine the two processes. (Edtion Note 10: See also my Mind at Large, ch. 8, for a similar discussion.-PL]

3. "It is useful, however, to make it clear that such systems are artificial ones creared the mind through social interaction and individual manipulation of symbols. The most basic of the systems, arithmetic, has been shown by Gödel to be incomplete. I would characterize the study d mathematics as Philip Davis and Reubin Hersh aptly put it in The Mathematical Experiense. the study of stable or invariant mental objects. Although our subtle materialism hardly asserts the these relations are not meaningful, it denies them a separate Platonic existence" (Edelman, 1902 p. 167). Edelman's impoverished view of World 3 is also betrayed in his assumption that cogaitin adaptation is exhausted by the problem of conceptualizing the world; theories, arguments, logial relations, etc. are left out of the account.

4. The 1976 Yearbook reported that during 1975 there had been a $9.7{ }^{\circ} \mathrm{c}$ growth in the number of Witness publishers over the previous year. But in 1976, after the prophetic failure of 1975, ther was only a $3.7 \%$ increase, and in 1977 there was a somewhat more than $1 \%$ decrease. In some countro the decrease was far greater. In the Philippines, for example, $20 \%$ of active Witnesses became inazivi Penton, 1985, p. 99). In interpreting these figures, one has to bear in mind that organizations the the Watch Tower Society do not consist of a static membership, but have people joining and learing prophecies me fact that naive new initiates are joining and that they need time to learn of the

5. Kramer points effect of a prophetic failure is diluted somewhat.

that the Sumerian city-state that this runs counter to the claim of a number of Far Eastern scholars all land and was in absolute was a totalitarian theocracy dominated by the temple, which ouned by a Russian scholar. in Ancient Mesopotamia, Moscow) Sch, whose work appeared in 1959 (Sumer: Societl and Sidt of tablets from pre-Sargonic $S$ w.) Scholars were misled by the fact that the overwhelming majonit! temples of Lagash, which deal ser, the Sumer of 2400 B.C.. are inventory documents from the number of documents showing solely with temple land and personnel. However. there are quite s

moveable property. (See Kramer, pp. 75-79.)
6. In Blanchard the city-states could buy and sell their land ani

phases of the moon over two a bone pressure plague was discovered. Symbols standing for the If this is a calendar, it is certainly a more complex acheraved in its surface (Marshack. 1985.1
swapping. 
7. Homo habilis, from 2.5 myBP. Endocasts from Home Habilis skulls show that the expansion of the brain after its predecessor, Australopithecus Africanus, was most notable in parts responsible for language: the inferior frontal lobule in the Broca area and the inferior parietal lobule in the Wernicke area (Tobias, 1983; Holloway, 1983).

8. See Popper's schema of language functions: expressive, signaling, descriptive, and argumentative $(1962$, pp. 134, 295). To be effective, even signaling (communication between one organism and another) must simulate the following of at least the law of non-contradiction. Thus there is plenty of scope for the delineation of intermediate stages in the evolution of logic.

9. Ralph Holloway of Columbia University, New York, uses a similar argument to link spoken language and tool-making, arguing that the cognitive processes underlying each are very similar. Both processes involve the sequential elaboration of component parts that, if inserted out of a prescribed order, make nonsense of the final product (Holloway, 1974, pp. 106-115).

10. David Miller has shown that in general two theories cannot be such that one is uniformly more accurate than the other. This is one of the problems of Popper's attempt at an explicit theory of verisimilitude. Nevertheless, we do seem able to say that the theory of a spherical earth is more truth-like than the flat-earth theory. See Miller, 1994. See also Tichý (1974) for a mathematical proof of the inadequacy of Popper's original proposal. There are also problems with information content comparison as such, where the content of a theory is defined in terms of the set of all the problems that a theory can answer. (See Popper, 1974, pp. 20-21, and Watkins, 1972.) Grünbaum (1976) and Miller (1975) have pointed to interesting cases where some questions that are decidable by a predecessor theory are undecidable by its successor.

11. As Munz (1985, p. 292) puts it: "since 'fitting nature' is not the criterion of selection in this case, there is a sort of inverse proportion between being selected and being non-fitting. The more absurd an invention, the more likely its usefulness as a social bond." Munz's argument can be put thusly: A society is more likely to survive if it has strong bonding between its individual members; bonding is strengthened by shared belief; the more distinctive the belief the stronger the bond; the more false a belief, the more distinctive it is. Thus societies with the most absurd theories are the most likely to survive. A society's ideas flourish if and only if, and to the extent that, the society flourishes. Thus the more successful ideas will be those that belong to the most successful societies. Thus the most successful ideas are the most absurd. I see the following problems with such a schema:

a) problems of cultural-group selectionism: the rate with which societies come into and go out of existence is not high enough to provide convincing evidence of such a pattern;

b) even if societies were in a continual life or death conflict, we would expect those with the best military technology to win, i.e., those whose military science had a good fit to reality, and thus for this reason science, technology and associated attitudes to truth, etc. to survive best;

c) a society, just like a person, may pass on its ideas before it dies;

d) soldiers are more confident and have high morale generally when they are properly equipped; there may be an underdog effect with the inferior groups feeling some kind of bond in misery, but this is hardly likely to enhance the copyability of its technology, etc.

12. One could argue that even mass advertising depends on this ancient method of personal recommendation. A mass TV advertisement of, say a new perfume, prompts a small percentage of viewers to try it. They like it. Then each of them tells his or her friends and each of these friends tells their friends, etc.

13. Watkins (1984, pp. 203-218) calls his requirement for theoretical unity "organic fertility." A theory is organically fertile if and only if however one divides the theory into two parts the whole 

theory has greater testable content than the sum of the testable contents of its two parts. We
note that Watkins' treatment is confined to empirically testable theories and so is straightforwardly applicable to theistic theories.

14. "In every type of civilization, every custom, material object, idea and belief fulfils vital function, has some task to accomplish, represents an indispensable part within a working whot (Malinowski, 1926).

15. In asserting that psychological states such as tastes are objective, I am not implying the they are physical, just that they have independent properties that can be correctly or incorreas. described, to which an organism can more or less accurately adjust and adapt. Indeed, this is fol consistent with Popper's three worlds schema, in which World 1 (the world of physical object World 2 (the world of psychological states), and World 3 (the world of abstract entities, such: numbers, theories, symphonies) have emerged one from the other (in the sequence $1,2,3$ ) in course of cosmological evolution. They can also influence one another, World 1 and 2 via Wots 3. But once in existence, the entities of these realms have properties independent of one another. A human being can adjust to a set of non-subjective facts (such as the tools available) plus a rant order of preferences either psychologically (abandoning the goal), or by directly altering World 1 , or by constructing a World 3 object (a theory or method) to change World 1 directly.

16. Our preference for sugar is an obvious exception to this rule. [Editor's Note 11: Although one could say that refined sugar appeals to a taste for nutrition which when satisfied in non-refined form-e.g., eating fruit-is evolutionarily quite appropriate. $-P L]$

17. Gary Becker has shown that a negative demand curve can be produced by various "irrational" decision rules-that markets can behave rationally even if individuals do not. In other words, negative demand curves and positive supply curves can be logically derived from other assumptions. My reply is that any set of data can be explained by any one of a logically infinite set of possible assumptions. We already knew this. Becker's main contribution is to have applied this philosophical insight to economics and supplied a particular alternative interpretation. However. there are independent arguments for our rationality, including those that use evolutionary theory. What is needed are experiments that discriminate between the rationality assumption and Becker's alternative. Furthermore, Becker's definition of "rational behavior" as "maximization of a consistent and transitive function" is debatable. Kaufman (1933, p. 390) argued that if $a$ is prefered to $b$, and $b$ is prefered to $c$, logically $a$ should be prefered to $c$. But if actually $c$ is preferred to $a$, we are faced with a type of action which is inconsistent and therefore irrational. But as Mises (1949) argued, some pairs of acts of an individual cannot be simultaneous. If in one action $a$ is preferred to $b$. and in another action $b$ to $c$, one cannot construct, however short the interval between the actions. a uniform scale of value in which $a$ is preferred to $b$, and $c$ is preferred to $c$. Value judgements change, sometimes rapidly. This runs the risk of making one's economics irrefutable. But to portray preferences as static does seem inaccurate. However, this might be possible if one had a theory aboul more stable "general" or "basic" desires that could be tested independently. Thus one might distinguish between very changeable desires for say, a particular car, and more stable desires, such as the desire for travel per se. Becker and Stigler (1977) have pursued this road with much success. I think that a combination of psychology and evolutionary theory may give us independently testable assumptions about these stable preferences.

18. Wittgenstein, in his early period, maintained that there were elementary propositions each of which mirrored an atomic fact. The set of all elementary propositions was thought to be logically independent and uniquely determined. This picture fits Dawkins' requirements perfectly. However, Black (1964) has shown that logically equivalent languages may have different elementary propositions. Nevertheless, although elementary propositions are not uniquely determined in ath absolute sense, they are still discrete in any particular language, and so the dreaded problem of
"blending" does not arise. (See Miller, 1977.) 
19. In discussing the birth trauma hypothesis of post Freudians and how they might respond to a refutation by redefining "birth trauma" as not due to the birth itself, but the shock of coming into the world. Gregory says: "Popper would object to [this] for then the hypothesis would have changed, rather than decently died..." Gregory then goes on to say, supposedly contra Popper, that perhaps redefining hypotheses is a way in which we keep the best parts of refuted theories. But Popper has always distinguished between the logical matter of refutation and the separate (though related) methodological question of when a theory ought to be abandoned or have the best (unrefuted) parts cannibalized and continue on. In Gregory's example, the refutation of the trauma theory is unaccepted, but is nevertheless, perhaps unintentionally, abandoned. The upshot is that confusion is created and knowledge does not grow as much as it would have if the refutation had been honestly and publicly accepted.

20. Levine, in his study of over 800 members of religious movements (1984), found that over $90 \%$ left within two years. Bird and Reimer (1983), in their study of 1,607 adults in Montreal, found that $75.5 \%$ of participants in new religious movements were no longer involved five years later. The defection rate ranged from $55.2 \%$ for Transcendental Meditation to $100 \%$ for the Church of Scientology.

\section{References}

Alchian, A. A. (1968) "Cost." International Encyclopedia of the Social Sciences, 3, 404-415.

Austin, J. (1962) How to Do Things With Words. Oxford: Clarendon.

Avron, A. (1990) "Relevance and Paraconsistency." Notre Dame Journal of Formal Logic, Spring, $168-202$.

Axelrod, R. (1984) The Evolution of Cooperation. New York: Basic Books.

Barker, E. (1988) "Defection from the Unification Church: Some Statistics and Distinctions," in Bromlet, D., ed. Falling from the Faith: Causes and Consequences of Religious Apostasy. Beverly Hills, CA: Sage.

Bartley, W. W., III (1962/1984) The Retreat to Commitment, 2nd. ed. La Salle, IL: Open Court. Bartley, W. W., III (1990) Unfathomed Knowledge, Unmeasured Wealth. La Salle, IL: Open Court. Beck, A. T. (1976) Cognitive Therapy and the Emotional Disorders. New York: International University Press.

Becker, G. \& Stigler, G. (1977) “De Gustibus Non Est Disputandum.” American Economic Review, 66.

Bird, F. \& Reimer, W. (1983) Of Gods and Men: New Religious Movements in the West. Macon, GA: Mercer University Press.

Black, M. (1964) A Companion to Wittgenstein's Tractatus. Cambridge, UK: Cambridge University Press.

Boole, G. (1854/1952) An Investigation of the Laws of Thought. La Salle, IL: Open Court. Boudon, R. (1989) The Analysis of Ideology. Chicago, IL: The University of Chicago Press.

Boyd, R. \& Richerson, P. J. (1985) Culture and the Evolutionary Process. Chicago, IL: University of Chicago Press.

Brunvand, J. H. (1989) Curses, Broiled Again! New York: Norton, 1989.

Campbell, D. T. (1960) "Blind Variation and Selective Retention in Creative Thought as in Other Knowledge Processes." Psychological Review, 67, 380-400.

Campbell, D. T. (1974) "Evolutionary Epistemology", in Schilpp, P., ed. The Philosophy of Karl Popper. La Salle, IL: Open Court, pp. 413-463.

Dawkins, R. (1976) The Selfish Gene. Oxford: Oxford University Press.

Dawkins, R. (1982) The Extended Phenotype. Oxford: Oxford University Press. 
Dawkins, R. (1993) "Is God a Computer Virus?" in Dahlbom, B., ed. Dennett and his Critlow Demystifying the Mind. London: Basil Blackwell.

Durkheim. E. (1915) The Elementary Forms of Religious Life. London: Allen and Unwin.

Edelman, G. M. (1987) Neural Darwinism: The Theory of Neuronal Group Selection. New York Basic Books.

Edelman, G. M. (1992) Bright Air, Brilliant Fire. New York: Basic Books.

Elster, J. (1982) "Belief, Bias and Ideology", in Hollis, M. \& Lukes, S., eds. Rationality and Relativism. Oxford: Basil Blackwell, pp. 123-148.

Festinger, L., Rieken, H. W. \& Schachter, S. (1956) When Prophecy Fails. Minneapolis, MN: University of Minnesota Press.

Frazer, J. (1922) The Golden Bough: A Study in Magic and Religion. London: Macmillan.

Freud, S. (1911) "Formulations on the Two Principles of Mental Functioning." Standard Edition of the Complete Works of Sigmund Freud, vol. 12, Strachey, J., trans. London; Hogarth

Freud, S. (1913/1991) Totem and Taboo. Strachey, J. trans. London: Ark.

Fries, J. (1828-1831) Neue oder anthropologische Kritik der Vernunft. Heidelberg, Germany. Christian Friedrich Winter.

Gibbon, E. (1776/1963) Decline and Fall of the Roman Empire. London: Pelican.

Goertzel, B. (1993) "Psychology and Logic." Journal of Social and Evolutionary Systems, 16 (4), 439-457.

Graham, A. C. (1989) Disputers of the Tao: Philosophical Arguments in Ancient China. La Salle, IL: Open Court.

Gregory, R. L., ed. (1987) The Oxford Companion to The Mind. New York: Oxford University Press.

Grünbaum, A. (1976) “Can a Theory Answer More Questions than One of its Rivals?” British Journal for the Philosophy of Science, 27, 1-23.

Hallpike, C. R. (1986) The Principles of Social Evolution. New York: Oxford University Press.

Hamilton, W. D. \& Axelrod, R. (1981) "The Evolution of Cooperation." Science, 211, 1390-13\%.

Hattiangadi, J. N. (1987) How is Language Possible? La Salle, IL: Open Court.

Hofstadter, D. R. (1983) “On Viral Sentences and Self-Replicating Structures." Scientific American, January.

Holloway, R. L. (1974) "The Casts of Fossil Hominid Brains." Scientific American, 231 (l), 106115.

Holloway, R. L. (1983) “Human Paleontological Evidence Relevant to Language Behavior.” Human Neurobiology, 2, 105-114.

Jarvie, I. (1972) Concepts and Society. London: Routledge and Kegan Paul.

Jarvie, I. \& Agassi, J. (1967) "The Problem of the Rationality of Magic." British Journal of Sociology, $8,2$.

Katz, D. (1937) Animals and Men. London: Longmans.

Kaufman, F. (1933) "On the Subject Matter of Economic Science." Econmica. 13, p. 390.

Kirzner, I. (1960) The Economic Point of View. Kansas City, MO: Sheed and Ward.

Kolakowski, L. (1978) Main Currents of Marxism. Oxford: Clarendon Press.

Kramer, S. (1963) The Sumerians: The History, Culture and Character. Chicago, IL: The University of Chicago Press.

Lakatos, I. (1970) "Falsification and the Methodology of Scientific Research Programmes," in Lakatos, I \& Musgrave, A., eds. Criticism and the Growth of Knowledge. Cambridge, UK: Cambridge University Press, pp. 91-196.

Levine, S. (1984) Radical Departures. San Diego, CA: Harcourt Brace Jovanovich.

Loparic, A. \& Da Costa, N. C. (1984) "Paraconsistency, Paracompleteness, and Valuation." Logique et Analyse, 27, 119-132. 

Lorenz, K. (1973) Die Ruckseite des Spiegels. Munich: R. Piper \& Co Verlag. (Behind the Mirror.
Methuen \& Co., 1977.)

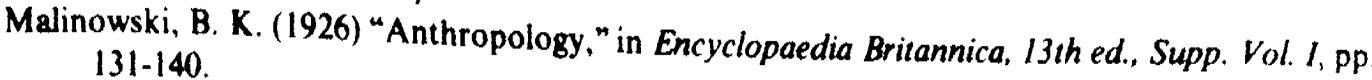

Marshack. A. (1985) Hierarchical Evolution of the Human Capacity. New York: American Musueum of Natural History.

McKenzie, R. B. \& Tullock, G. (1975/1981) The New World of Economics, 3rd. ed. Homewood IL: Richard D. Irwin.

Meyerson, D. (1991) False Consciousness. Oxford: Clarendon Press.

Meyerson, E. (1908) Identité et realité. Paris: Vrin.

Miller, D. (1975) "The Accuracy of Predictions," Synthese, 30, 159-191.

Miller, D. (1977) "The Uniqueness of Atomic Facts in Wittgenstein's Tractatus." Theoria, 53, part 3.

Miller, D. (1982) "Conjectural Knowledge: Popper's Solution of the Problem of Induction," in Levinson, P., ed. In Pursuit of Truth: Essays on the Philosophy of Karl Popper. Atlantic Highlands, NJ: Humanities, pp. 17-49.

Miller, D. (1994) Critical Rationalism: A Restatement and Defense. La Salle, IL: Open Court.

Mises, L. v. (1949) Human Action. London: William Hodge \& Co.

Monod, J. (1970) Chance and Necessity. London: Fontana.

Munz, P. (1985) Our Knowledge of the Growth of Knowledge: Popper or Wittgenstein. London. Routledge and Kegan Paul.

O'Hear, A. (1988) "The Evolution of Knowledge," Critical Review, 2 (l), 78-91.

Pears, D. (1984) Motivated Irrationality. New York: Oxford University Press.

Penton, M. J. (1985/ 1988) Apocalypse Delayed. Toronto: University of Toronto Press.

Percival, R. (1991) "Openness to Argument. Ph.D. diss. London School of Economics and Political Science.

Plato. Phaedrus \& Letters VII and VIII. Penguin edition, 1988.

Popper, K. (1934/1977) Logic of Scientific Discovery. London: Hutchinson.

Popper, K. (1945) The Open Society and Its Enemies. London: Routledge.

Popper, K. (1963/1969) Conjectures and Refutations. London: Routledge and Kegan Paul.

Popper, K. (1972/1979) Objective Knowledge. Oxford: Oxford University Press.

Popper, K. (1976) Unended Quest. London: Fontana/Collins.

Popper, K. (1990) A World of Propensities. Bristol, UK: Thoemmes Antiquarian Books Ltd.

Radnitzky, G. (1986) "Towards an 'Economic' Theory of Methodology," Methodology and Science, 19, 124-147.

Radnitzky, G. \& Bartley, W. W., III, eds. (1987) Evolutionary Epistemology, Rationality, and the Sociology of Knowledge. La Salle, IL: Open Cour.

Robins, L. (1935) An Essay on the Nature and Significance of Economic Science. London: Macmillan.

Ruse, M. (1986) Taking Darwin Seriously. New York: Blackwell.

Searle, J. (1984) Minds, Brains and Science. London: Penguin Books.

Seligman, M. \& Hager, J., eds. Biological Boundaries of Learning. New York: Appleton-CenturyCrofts.

Simon, J. (1993) Good Mood. La Salle: Open Court.

Spiro, M. E. (1979) Gender and Culture: Kibbutz Women Revisited. Durham NC: Duke University Press.

Staal, J. F. (1967) "Indian Logic," in Edwards, P., ed. Encyclopaedia of Philosophy, Vol. 4. New York: Collier Macmillan, pp. 520-523.

Steele, D. R. (1988) "How We Got Here." Critical Review, 2 (l).

Steele, D. R. (1992) From Marx to Mises. La Salle, IL: Open Court. 
Tichý, P. (1974) "On Popper's Definitions of Verisimilitude." British Journal for the Phtt of Science. 25, 155-160.

Tobias, P. V. (1983) "Recent Advances in the Evolution of the Hominids with Special Re to Brain and Speech." in Chagas, C., ed. Recent Advances in the Evolution of $A$ Vatican City: Pontificiae Academiae Scientiarum Scripta Varia 50, pp. 85-140.

Wächtershäuser, G. (1984) "Light and Life: On the Nutritional Origins of Sensory Perception. presented at a Symposium at the 150th National Meeting of the American Associa the Advancement of Science. [Reprinted in Radnitzky \& Bartley, 1987.]

Watkins, J. W. N. (1972/1979) [Private communication to Popper; recounted by Popper in 1972/1979.]

Watkins, J. W. N. (1984) Science and Scepticism. London: Hutchinson.

Weber, M. (1968) Max Weber on Charisma and Institution Building; Selected Papers. $\mathrm{C}$ IL: University of Chicago Press.

Wells, G. A. (1988) Religious Postures. La Salle, IL: Open Court.

Zahar, E. (1989) Einstein's Revolution. La Salle, IL: Open Court.

\section{Acknowledgements}

I thank David McDonagh, Jan Lester, David Miller, David Ramsay Steele, Minogue, and Shirley Toole for critical comment and discussion on the prob rationality.

\section{About the Author}

Dr. Ray Scott Percival is organizer of the Annual Conference on the Philosophy 9 Karl Popper, Associate Editor of the Popper Newsletter, and on the Editorial Bow the Journal of Social and Evolutionary Systems. His reviews appear in such publical as The New Scientist and Nature. 
Tichý, P. (1974) "On Popper's Definitions of Verisimilitude." British Journal for the Philosophy
of Science. 25, 155-160.

Tobias, P. V. (1983) "Recent Advances in the Evolution of the Hominids with Special Referem to Brain and Speech." in Chagas, C., ed. Recent Advances in the Evolution of Primates.
Vatican City: Pontificiae Academiae Scientiarum Scripta Varia 50, pp. 85-140. presented at a Symposium at the 150th National Meeting of the American Association for
the Advancement of Science. [Reprinted in Radnitzky \& Bartley, 1987.] Watkins, J. W. N. (1972/1979) [Private communication to Popper; recounted by Popper in Popper,
1972/1979.]

Watkins, J. W. N. (1984) Science and Scepticism. London: Hutchinson.

Weber, M. (1968) Max Weber on Charisma and Institution Building; Selected Papers. Chicago,
IL: University of Chicago Press.

Wells, G. A. (1988) Religious Postures. La Salle, IL: Open Court.

Zahar, E. (1989) Einstein's Revolution. La Salle, IL: Open Court.

\section{Acknowledgements}

I thank David McDonagh, Jan Lester, David Miller, David Ramsay Steele, Kenneth Minogue, and Shirley Toole for critical comment and discussion on the problem of rationality.

\section{About the Author}

Dr. Ray Scott Percival is organizer of the Annual Conference on the Philosophy of Sir Karl Popper, Associate Editor of the Popper Newsletter, and on the Editorial Board of the Journal of Social and Evolutionary Systems. His reviews appear in such publication as The New Scientist and Nature. 